Article

\title{
Development of Drift-Reducing Spouts For Vineyard Pneumatic Sprayers: Measurement of Droplet Size Spectra Generated and Their Classification
}

\author{
Marco Grella ${ }^{1, *(\mathbb{D})}$, Antonio Miranda-Fuentes ${ }^{2}$, Paolo Marucco ${ }^{1}$, Paolo Balsari ${ }^{1}$ \\ and Fabrizio Gioelli ${ }^{1}$ (D) \\ 1 Department of Agricultural, Forest and Food Sciences (DiSAFA), University of Turin (UNITO), Largo Paolo \\ Braccini 2, 10095 Grugliasco, Italy; paolo.marucco@unito.it (P.M.); paolo.balsari@unito.it (P.B.); \\ fabrizio.gioelli@unito.it (F.G.) \\ 2 Department of Rural Engineering, University of Cordoba, Edf. Leonardo da Vinci, Ctra. Nacional IV, km 396, \\ 10014 Cordoba, Spain; g62mifua@uco.es \\ * Correspondence: marco.grella@unito.it; Tel.: +39-011-670-8610
}

Received: 9 September 2020; Accepted: 2 November 2020; Published: 4 November 2020

Featured Application: The newly designed pneumatic spout generates droplet-sized spectra in a wide range of options, from very fine to very coarse, thus providing farmers with a real possibility for accomplishing the drift-reducing EU policy requirements when using pneumatic sprayers.

Abstract: Pneumatic spraying is especially sensitive to spray drift due to the production of small droplets that can be easily blown away from the treated field by the wind. Two prototypes of environmentally friendly pneumatic spouts were developed. The present work aims to check the effect of the spout modifications on the spray quality, to test the convenience of setting the liquid hose out of the spout in cannon-type and hand-type pneumatic nozzles and its effect on the droplet size, homogeneity and driftability in laboratory conditions. Laboratory trials simulating a real sprayer were conducted to test the influence of the hose insertion position (HP), including conventional $(\mathrm{CP})$, alternative $(\mathrm{AP})$, outer $(\mathrm{OP})$ and extreme $(\mathrm{XP})$, as well as the liquid flow rate (LFR) and the airflow speed (AS) on the droplet size (D50, D10 and D90), homogeneity and driftability (V100). Concurrently, the droplet size spectra obtained by the combination of aforementioned parameters (HP $\times$ LFR $\times$ AS) in both nozzles were also classified according to the ASABE S572.1. Results showed a marked reduction of AS outside the air spout, which led to droplet size increase. This hypothesis was confirmed by the droplet size spectra measured (D50, D10, D90 and V100). A clear influence of HP was found on every dependent variable, including those related with the droplet size. In both nozzles, the longer the distance to $\mathrm{CP}$, the coarser the sprayed drops. Moreover, LFR and AS significantly increased and reduced droplet size, respectively. A higher heterogeneity in the generated drops was obtained in XP. This position yielded V100 values similar to those of the hydraulic low-drift nozzles, showing an effective drift reduction potential. The classification underlines that the variation of HP, alongside AS and LFR, allowed varying the spray quality from very fine to coarse/very coarse, providing farmers with a wide range of options to match the drift-reducing environmental requirements and the treatment specifications for every spray application.

Keywords: pesticide application; pneumatic nozzle; homogeneity; airflow speed; liquid flow rate; spray drift reducing; spray quality 


\section{Introduction}

Grape production represents one of the most important agricultural businesses worldwide, with 7.5 million hectares and five countries representing $50 \%$ of the world vineyard harvested area: Spain $(13 \%)$, China (11\%), France (10\%), Italy (9\%) and Turkey (7\%) [1]. However, considering the total grape production, Italy ranks second after China, with 8.4 and $13.7 \mathrm{Mt}$ respectively, followed by USA, France and Spain [1]. Considering wine grapes, only the EU ranks first with $61.3 \%$ of total world production [1].

Producing high-quality food in a safe manner is one of the most important goals in modern agriculture [2]. Indeed, the high number of spray applications during the vegetative season in intensive production systems determines a massive Plant Protection Product (PPP) use that can cause undesirable effects related to pesticide residues on food and adverse effects to the environment.

At present, PPP spraying is a commonly used technique to control pests and diseases in commercial crops. Nevertheless, spraying is a complex process in which several factors interfere [3]. For that reason, controlling all factors is nearly impossible, and as a result PPP applications could be inefficient. This fact led the European Authorities to develop Directive 2009/128/EC on sustainable use of pesticides [4]. This Directive specifies that pesticide applications should always consider the principles of integrated pest control strategies. Among these, efficiency in the pesticide application necessarily plays a major role that is not completely matched nowadays. Among the main parameters to be considered regarding spraying efficiency, liquid flow rate, airflow rate and droplet size are three of the most important [5-14], along with the forward speed $[15,16]$.

Indeed, during spray applications in bush/tree crops with conventional sprayers, only a limited fraction of the total amount of PPP is deposited on the intended target according to the canopy characteristics $[7,17]$. Therefore, part of the applied PPP can be transported outside the sprayed area by the action of air currents during the application process as spray drift [18]. Some authors have quantified that, during a spray application, up to $50 \%$ of the total applied PPP spray mixture can be lost to the air from the targeted site to a non-target receptor site [19-27]. In addition to the more localized movement of agrochemical residues in turbulent air masses downwind of the application area, residues can also become concentrated in inversions or stable air masses and be transported at long distances [28]. Another fraction could end up as spray deposition on the ground, directly in the field tractor path and underneath target tree rows or indirectly in the adjacent area $[5-7,20,29,30]$. Among spray losses, spray drift remains the most troubling, as it is really difficult to control [23,31-36], especially in 3D crops such as vineyards [37]. Due to the importance to minimize PPP spray drift generation, strong efforts have been undertaken to properly study this phenomenon and to give adequate advice to farmers around Europe [38].

Among the different factors influencing spray drift, wind speed and direction are the main ones [39]. The higher the wind speed, the higher carrying effect it will have for droplets; therefore, the spray drift risk increases $[40,41]$. A solution to avoid spray drift is necessary, and it relies on not spraying when the wind is present. Nonetheless, reality is not so simple, as there are many situations in which pesticide needs to be applied a certain day or in a very narrow time window, so the farmer needs to spray even if the wind conditions are not favorable. Consequently, they must act on technical factors (those controlled by the applicator) through a proper adjustment of the spraying equipment [19,42].

Droplet size has proven to be the most effective factor in reducing spray drift $[12,20,23-25,28,33,43]$. The main reason why this factor affects spray drift is the weight of the emitted drops: the bigger the size, the higher the weight and, therefore, the lower the drift, as the carrying effect of wind will be lower with heavier drops [34]. This was the way followed to develop drift-reducing hydraulic nozzles decades ago. These nozzles produce coarser droplets than the conventional ones do. This result is achieved either by (i) decreasing liquid pressure in the nozzles chamber (drift-guard (DG) nozzles) or (ii) by generating air-inflated drops (air-inclusion (AI) nozzles). As it is the most common strategy to reduce PPP drift, recently different studies have been focused to demonstrate that drift-reducing nozzles generate important spray savings while keeping the necessary spray deposition to ensure the 
biological efficacy of treatments [44,45]. Nevertheless, some farmers still prefer conventional nozzles as low-size drops generate higher coverage on the leaf surface. As a consequence [46], it is commonly believed they can achieve a higher efficacy against pest and diseases. Several studies have instead showed that droplet size could be increased to reduce spray drift risks without compromising the treatment efficacy [35,45,47], especially in unfavorable environmental conditions [48].

Pneumatic spraying is a well-known technique for its fine droplet size generation. As aforementioned, small droplets are generally requested by the farmers to achieve a uniform target spray coverage that is essential for contact PPP; thus, this technique is very widespread, especially among large-farm vine growers in America and Europe [49,50]. In Italy there are large areas in which vineyard treatments are performed almost exclusively with pneumatic sprayers [51]. The small droplet size produced by this type of nozzle increases the drift risk with respect to the hydraulic nozzles [52]. Thus, whilst the droplet volume median diameter (VMD) generated by conventional hydraulic hollow-cone nozzles typically ranges from 100 to $200 \mu \mathrm{m}$, for pneumatic nozzles the VMD is generally below $100 \mu \mathrm{m}$ [53-55]. This threshold of $100 \mu \mathrm{m}$ is broadly considered as the minimum diameter that droplets should have to reasonably limit the spray drift risk $[56,57]$. Therefore, a droplet population with diameters below this value is subjected to losses by drift even with slow environmental air currents.

In order to better understand the droplet population generated by pneumatic nozzles, Balsari et al. [53] investigated and quantified the effect of the main operational parameters, namely the liquid flow rate and the airflow rate, on different variables related to the droplet population, mainly their size and homogeneity. They also assessed the driftability of the drops according to the aforementioned parameters. In order to do so, they developed a laboratory test bench to simulate a real pneumatic sprayer and to test different combinations of parameters, measuring the droplet diameter with a laser device. Once the pneumatic spray behavior was well understood, the same authors planned a strategy to increase droplet size in case of high-speed environmental wind conditions [55]. The idea was to alter the liquid release position inside the air spout, taking advantage of the air speed decrease across the outermost section of the spout [55]. They obtained very promising results, recently confirmed by field trials [58], that demonstrated this strategy could have an important potential to properly reduce spray drift in pneumatic spraying thanks to the droplet size spectra increase.

The main objective of this work was to develop, for the first time, drift-reducing spouts, namely cannon and hand spout types, for vineyard pneumatic sprayers. In detail we evaluated i) the possibility to increase droplets size by adjusting the water income position out of the nozzle spouts and ii) its effect on the droplet size population and homogeneity. Furthermore, the feasibility of introducing alternative positions for the liquid hose in order to achieve different droplet size spectra populations and then different capabilities of drift reductions according to the liquid hose positions were investigated.

\section{Materials and Methods}

\subsection{Trial Location and Spraying Equipment}

The laboratory trial was carried out in the facilities of the Department of Agricultural, Forest and Food Sciences (DiSAFA) of the University of Turin located in Grugliasco (Turin, Italy). A test bench was used to simulate the working conditions of the pneumatic sprayer. This test bench consisted of both pneumatic and hydraulic circuits mounted over three different spaces, as shown with detail in Miranda-Fuentes et al. [55]. These spaces included a spraying area, a droplet size measurement area and a control and data acquisition room.

The test bench liquid circuit simulated those mounted in real pneumatic sprayers, including a water tank, a membrane pump AR 202 (Annovi Reverberi S.p.a, Modena, Italy) driven by an electric engine equipped with pressure regulation valves, and a manometer characterized by $0.02 \mathrm{MPa}$ resolution to precisely control the liquid pressure. The test bench ended up in the liquid hose inserted in the air spout of the pneumatic circuit. The liquid flow rate was controlled through a plastic disc with 
calibrated holes in its perimeter. The air assistance to achieve the spray in the test bench consisted of a centrifugal fan $500 \mathrm{~mm}$ diameter (CIMA S.p.a., Pavia, Italy) controlled by a central unit, in which the electric intensity flowing to the driving electric engine, and proportionally the rotary speed of the fan, could be manually adjusted. This control box could set the rotary speed $\left(\mathrm{rev} \mathrm{min}^{-1}\right)$ of the electric engine, measured by a laser tachometer integrated in the system. Thus, even when the control parameter was the amperage, the rotary speed was the indicator to manually regulate the system. As it was previously mentioned, both circuits merged in the air spout, in which the liquid was released through the liquid hose at constant pressure. The air spouts tested included two different types: a cannon-type spout and a hand-type spout (Figure 1a) generally installed on the spray head TC.2M2C.50P (Cima S.p.a., Pavia, Italy). These two kinds of spouts are usually simultaneously employed in the commercial pneumatic sprayers operating in vineyards, as shown in Figure $1 \mathrm{~b}$.

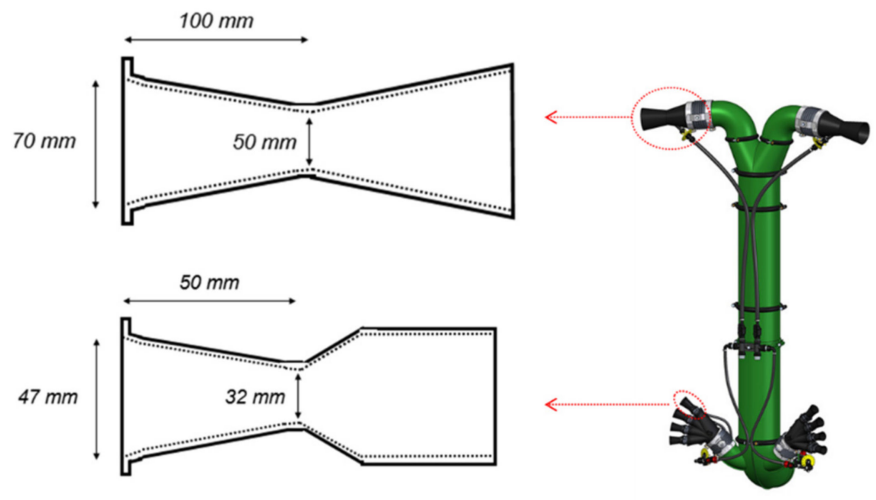

(a)

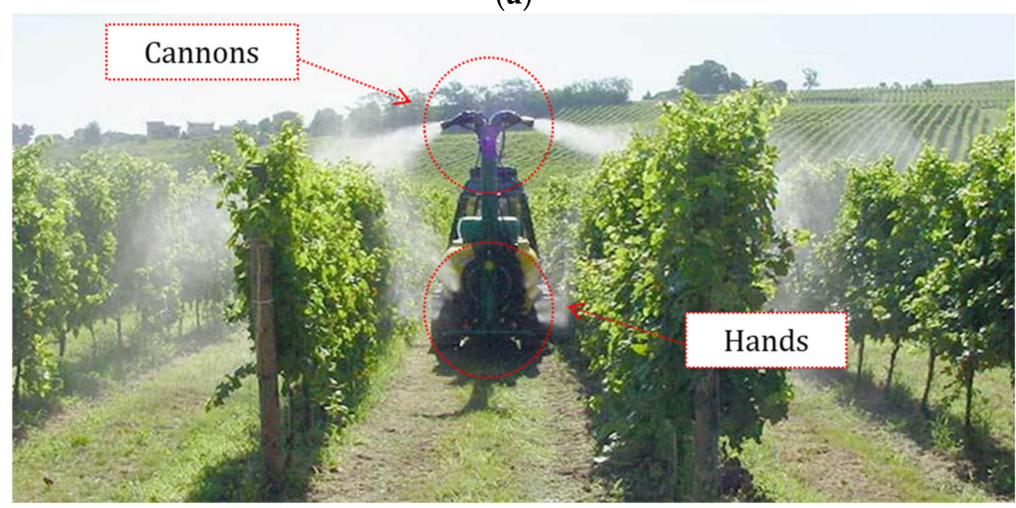

(b)

Figure 1. (a) Cannon-type and hand-type spouts mounted on the spray head TC.2M2C.50P for (b) multiple-row spray application in a vineyard.

These spouts were conveniently modified to alter the insertion position of the liquid hose, as it showed to have a major importance in the generated droplet size in cannon spouts [55]. The insertion position was, consequently, established as the main variable of the study, and it was called "hose position" (HP). It presented four possible levels in each spout type, called "conventional position" (CP), "alternative position" (AP), "out position" (OP) and "extreme position" (XP), as shown in Figure 2a. The $\mathrm{CP}$ position corresponds to that established by the manufacturer for the commercial equipment (Figure 2b,c). The other hose positions, namely AP, OP and XP, varied according to the spout type, as shown in Figure $2 b$ for the cannon and in Figure $2 \mathrm{c}$ for the hand spouts. In particular, in both spout-types, the AP corresponds with the one in which the outermost part of the hose is placed coincident with the border of the air spout (Figure $2 b, c)$, and the XP was experimentally set as the maximum distance in which a uniform liquid atomization could be achieved. This distance value was experimentally found by moving the liquid hose out of the air spout along its longitudinal axle 
through a rail in steps of $5 \mathrm{~mm}$ and the droplet size spectra measured in each position. Once this maximum distance was exceeded, the spray cloud changed drastically, appearing as extremely coarse droplets and losing the normal distribution. The $\mathrm{OP}$ was set at an intermediate distance between the $\mathrm{AP}$ and the XP (Figure 2b,c).

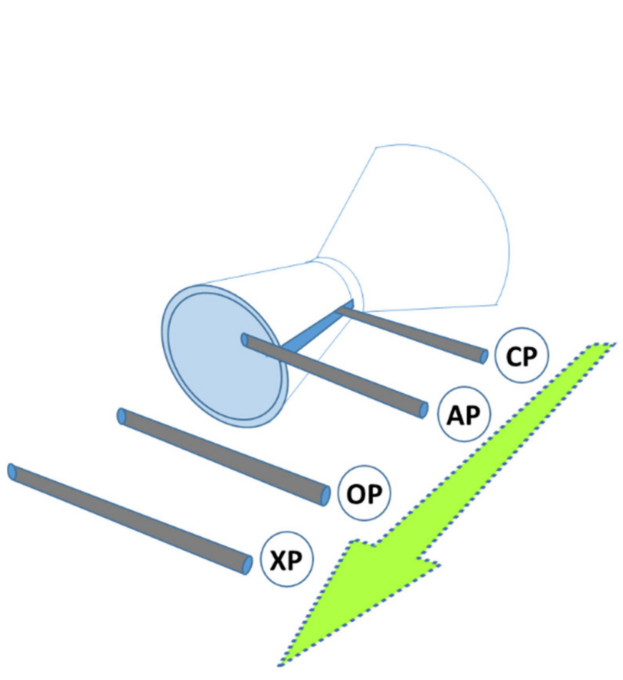

(a)

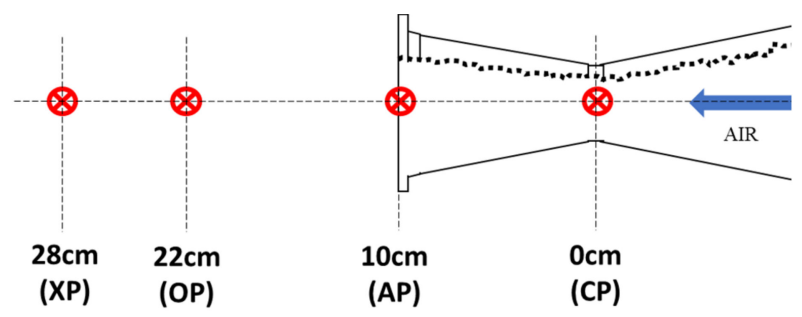

(b)

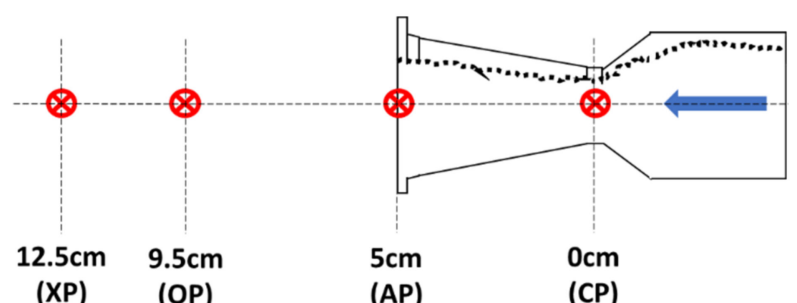

(c)

Figure 2. (a) Liquid hose positions from the inner to the outer part of spouts (green arrow): conventional position $(\mathrm{CP})(0 \mathrm{~cm}$ reference) passing through alternative position (AP), out position (OP) and extreme position $(\mathrm{XP})$. Distances $(\mathrm{cm})$ from the reference position were different for $(\mathbf{b})$ the cannon-type and $(\mathbf{c})$ the hand-type spouts.

\subsection{Droplet Size Spectra and Airflow Speed Measurements}

The droplet size spectra were measured with a Malvern Spraytec ${ }^{\circledR}$ laser diffraction system STP5342 (Malvern Instruments Ltd., Worcestershire, UK) (Figure 3a). The instrument has a maximum measurement frequency of $10 \mathrm{kHz}$ and a measurement range of 0 to $2000 \mu \mathrm{m}$. The instrument includes software (SprayTec Software v3.30, Malvern) for managing the data acquisition and charting. This software directly acquired the droplet size parameters D50 (or Volumetric Mean Diameter, VMD), D10 and D90. It also calculated V100, the fraction of the spray with droplets below $100 \mu \mathrm{m}$ in diameter, which easily can be blown away by the wind according to different authors [56,57]. The droplet homogeneity could also be drawn from the aforementioned droplet size parameters, if expressed as the RSPAN Factor (RSF), which can be calculated as shown in Equation (1) [12,59].

$$
R S F=\frac{D 90-D 10}{D 50}
$$

where RSF is dimensionless, and D90, D10 and D50 are expressed in $\mu \mathrm{m}$. 


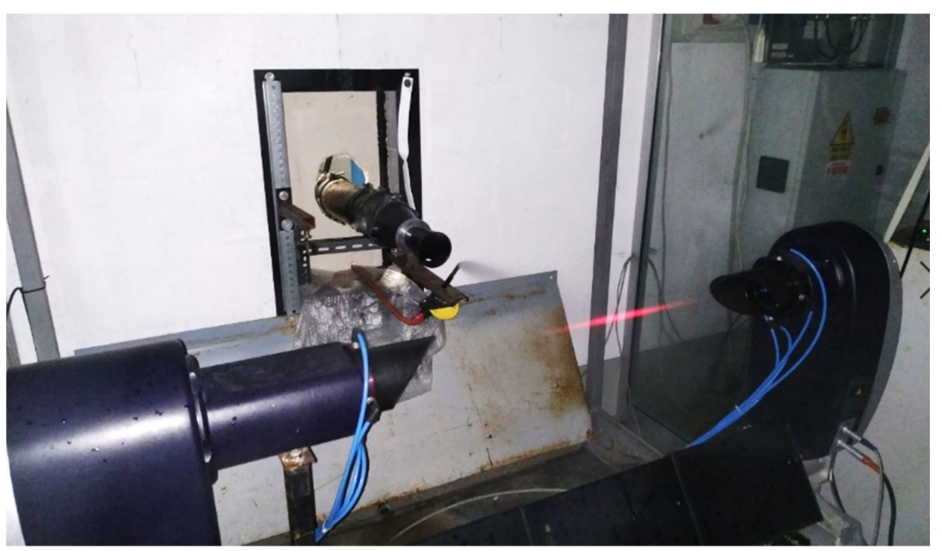

(a)

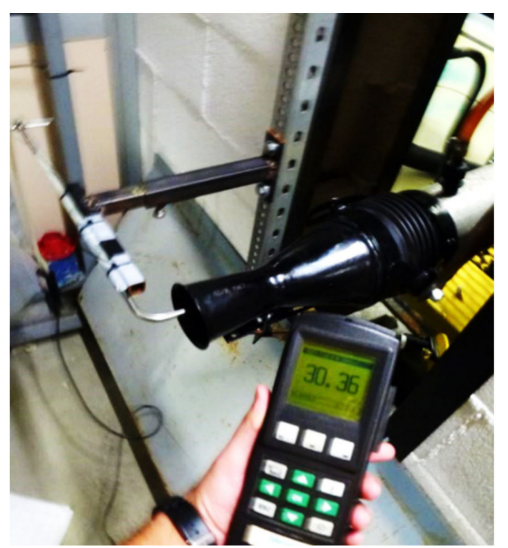

(b)

Figure 3. (a) Malvern Spraytech ${ }^{\circledR}$ laser diffraction system STP5342 for the measurements of droplet size spectra and (b) Testo 400 Pitot-tube-based anemometer for the measurements of airflow speed generated by both cannon-type and hand-type spouts.

The conventional hydraulic hollow cone nozzle Albuz ${ }^{\circledR}$ ATR lilac and the air-induction Albuz ${ }^{\circledR}$ TVI 8001 (CoorsTek Inc., Evereux, France) both operated at 0.7 MPa pressure, were selected as reference conventional spray technology for the comparison with the droplet size spectra investigated using the modified pneumatic spouts. In particular, the ATR lilac nozzle is well known to produce very fine (VF) spray quality, likewise the TVI 8001 nozzle is well known as a drift-reducing nozzle for the ultra-coarse (UC) spray quality generated [43]. Furthermore, the Albuz ${ }^{\circledR}$ ATR lilac was studied by other authors, and it is widely used by farmers with conventional hydraulic air-assisted sprayers both in vineyards and orchards [60]. The droplet size spectra generated by the reference nozzle were measured using the same laser diffraction system device described above and the methodology usually applied for the measurements of droplet size spectra generated by hydraulic nozzles, fully detailed in Grella et al. [25].

The measurement of the airflow speed was performed with a Pitot-tube-based anemometer Testo 400 (Testo SE \& Co. KGaA, Lenzkirch, Germany) (Figure 3b) at $1 \mathrm{~Hz}$ frequency with a measurement resolution of $\pm 0.01 \mathrm{hPa}$, a differential pressure corresponding to $1.28 \mathrm{~m} \mathrm{~s}^{-1}$, and a measurement range of up to $+2000 \mathrm{hPa}\left(571.43 \mathrm{~m} \mathrm{~s}^{-1}\right)$. The instrument was fixed to an ad hoc support developed by the researchers with some modifications to properly adapt it to the experiment [55]. The main advantage of this support was the possibility to keep the air speed measurement instrument in the center of the air spout (Figure 3b), avoiding errors that could deeply affect the measurements when holding it manually. The modifications in the instrument were essentially aimed at an enlargement of the holding tube to measure speed in the outermost position of the liquid hose (XP). Thus, the airflow speeds were measured along the central axis in six positions, corresponding to $0,5,10,16,22$ and 28 $\mathrm{cm}$ to the $\mathrm{CP}$ for the cannon-type spout and in five positions, corresponding to $0,2.5,5.0,9.5$ and 12.5 $\mathrm{cm}$ in a single spout for the hand-type nozzle. Preliminary trials were conducted to ensure the airflows generated individually by the four spouts that composed the hand-type nozzle were comparable. In each sampling position, the data were recorded for $60 \mathrm{~s}$ per each of the three replicates performed.

\subsection{Spray Parameters, Experimental Design and Settings Used During Trials}

Three different liquid flow rates (LFRs) were investigated, namely 1.00, 1.64 and 2.67 $\mathrm{L} \mathrm{min}^{-1}$. The intended LFR were obtained setting the liquid circuit pressure at $0.1 \mathrm{MPa}$ and using the liquid flow regulator disc (a plastic disc with calibrated holes in its perimeter) in positions 3,5 and 7 , respectively (Table 1). As mentioned above, four HPs were tested in both pneumatic nozzle types, namely CP, AP, $\mathrm{OP}$ and XP (Table 1). The intended exact positions of liquid hose, relative to the spout, were guaranteed thanks to a support integral with the spout body (Figure 3a). Concurrently, four AS were tested, namely 
81.3, 90.0, 100.2 and $109.2 \mathrm{~m} \mathrm{~s}^{-1}$ for the cannon-type nozzle and $57.9,64.6,74.3$ and $84.2 \mathrm{~m} \mathrm{~s}^{-1}$ for the hand-type nozzle. The tested AS values were referred to the reference position (CP), since the increase in spout section diameter deeply affects the decrease of AS along the spout body [55]. The intended AS were obtained properly setting the test bench fan rotary speed to simulate real conditions during spray application. Therefore, the main complexity was to adjust the test bench to make sure it matched the working parameters present in a real sprayer. There are many pneumatic circuit parameters that could be compared in both the bench and the sprayer, but the most representative and the one that ensures an equivalency in the working conditions is the air pressure. Thus, air pressure measurements were done to adjust both systems for every kind of pneumatic nozzle. The fully explained details of the calibration for both cannon- and hand-type nozzles along with the calibration results can be found in Balsari et al. [53] and Miranda-Fuentes et al. [55]. The air pressure measurements were performed with a manometer with a measurement resolution of $\pm 1 \mathrm{~mm} \mathrm{H}_{2} \mathrm{O}$, which was attached to a plastic piece fixed to the nozzle in every case. These pieces were large enough to reach the central part of both air spouts. The air pressure was measured for different Power Take Off (PTO) speed values in order to match the intended AS values previously measured in the real sprayer. According to those measurements, for laboratory trials the test bench fan rotary speeds were set at 541, 598, 663 and 720 rev $\mathrm{min}^{-1}$ for the cannon-type nozzle and at 488, 536, 609 and $677 \mathrm{rev} \mathrm{min}^{-1}$ for the hand-type nozzle, respectively. The operating parameters assessed are listed in Table 1.

Table 1. Operating parameter values of the two nozzle types used in laboratory trials.

\begin{tabular}{ccccc}
\hline & Parameter & Levels & Regulation Basis & Test Settings \\
\hline \multirow{3}{*}{ Cannon nozzle } & LFR & $1.00 / 1.64 / 2.67 \mathrm{~L} \mathrm{~min}^{-1}$ & Flow regulator disc & Positions $3 / 5 / 7$ \\
& AS & $81.3 / 90.0 / 100.2 / 109.2 \mathrm{~m} \mathrm{~s}^{-1}$ & Fan rotary speed & $541 / 598 / 663 / 720 \mathrm{rev} \mathrm{min}^{-1}$ \\
& HP & $0 / 10 / 22 / 28 \mathrm{~cm}^{* *}$ & Hose support & $\mathrm{CP} / \mathrm{AP} / \mathrm{OP} / \mathrm{XP} * * *$ \\
\hline \multirow{3}{*}{ Hand nozzle } & LFR & $0.84 / 1.33 / 2.07 \mathrm{~L} \mathrm{~min}^{-1}$ & Flow regulator disc & Positions $3 / 5 / 7$ \\
& AS & $57.9 / 64.6 / 74.3 / 84.2 \mathrm{~m} \mathrm{~s}^{-1}$ & Fan rotary speed & $488 / 536 / 609 / 677 \mathrm{rev} \mathrm{min}^{-1}$ \\
& HP & $0 / 5 / 9.5 / 12.5 \mathrm{~cm}^{* *}$ & Hose support & $\mathrm{CP} / \mathrm{AP} / \mathrm{OP} / \mathrm{XP} * * *$ \\
\hline
\end{tabular}

${ }^{*}$ LFR: liquid flow rate, AS: Air speed, HP: liquid hose position. ${ }^{* *}$ Distance from the conventional position $(\mathrm{CP}) .{ }^{* * *}$

$\mathrm{CP}$ : conventional position, AP: alternative position, OP: out position, XP: extreme position.

The experimental design was completely randomized, as no restrictions were present when measuring the droplet parameters (D50, D10, D90, RSF and V100) for a given combination of values of the independent variables (HP, LFR and AS; Table 1) in each studied pneumatic nozzle. The treatment order was randomized to avoid possible influence of external factors not considered in the design. The dependent variables were the droplet size parameters (i.e., D50, D10 and D90), the droplet homogeneity, given by the RSF, and the droplet driftability, given by the V100 parameter.

The trial began with the air spout placement, and it was conducted in two steps. In the first one, the airflow rate was established by adjusting the fan's rotary speed to the values obtained in the calibration $[53,55]$. The air speed was then measured in different positions using the Pitot tube, as described before. In the second step, the spray was enabled, and a $30 \mathrm{~s}$ time was given to the system to stabilize. Once the time had passed, the laser diffraction instrument was settled at the most appropriate distance from the spout (50 cm in accordance to previous trials [55]), and a total of 30 measurements were taken at $1 \mathrm{~Hz}$ acquisition frequency. The operational parameters (Table 1) were then combined to test every possible combination. In total, 48 configurations were tested for each spout type, deriving from the combination of different LFR, AS and HP. Three test replicates for each spout configuration were done.

\subsection{Data Analysis}

The data were recorded by Malvern Spraytech ${ }^{\circledR}$ software, while a special macro was developed in R-Studio [61] to automatically import and compile the data of every replication with their work parameter combination labels. Data analysis was performed in IBM SPSS Statistics v25 [62]. Normality 
and homoscedasticity of data were checked by using Shapiro-Wilk and Levene tests ( $\alpha=0.05$ in both cases). Graphs were done with the SPSS and Excel graph editor.

A three-way ANOVA test $(\alpha=0.05)$ was run to test the influence of the three factors (HP, LFR and AS) on every single dependent parameter (D50, D10, D90, RSF and V100). A FREGW (Ryan-Einot-Gabriel-Welsh F) test $(\alpha=0.05)$ was then applied to set the homogeneous groups. Correlations were developed between D50 and V100 for both pneumatic nozzles tested.

The cumulative sprayed volume curves, obtained by each tested configuration together with the reference hydraulic nozzles were compared with American Society of Agricultural and Biological Engineers (ASABE) nozzle classifications (ASABE S572.1) [63].

\section{Results and Discussion}

\subsection{Airflow Speed Drop Along the Spouts}

The airflow speeds measured along the longitudinal axle of cannon and hand spouts are graphed separately in Figure 4. Specifically, Figure 4a shows an important decrease in the air speed from the inner to the outermost position for the cannon-type nozzle (about $55 \%$ in every case). Nevertheless, this decrease was not constant along the axle, registering a slight slope between 5 and $10 \mathrm{~cm}$ from the inner position and very important slopes from $16 \mathrm{~cm}$ on (Figure 4a). Thus, the speed decreased at a variable rate ranging from 0 to $3.67 \mathrm{~m} \mathrm{~s}^{-1} \mathrm{~cm}^{-1}$. The effect of the nozzle border on the speed decrease was noticeable: the air speed decrease was less extreme near of the spout border, becoming more important in the $12 \mathrm{~cm}$ after the first $6 \mathrm{~cm}$ interval. This effect could be due to a border effect of air enclosure before spreading out of the main current direction in the following sections. Concurrently, Figure $4 \mathrm{~b}$ shows the response of the air speed in the hand-type nozzle. The two first sections, between the $\mathrm{OP}$ and the $\mathrm{AP}$, kept the air speed relatively constant, with less than $10 \%$ decrease in total in the most extreme case ( $677 \mathrm{rev} \mathrm{min}^{-1}$ of the test bench, Figure $\left.4 \mathrm{~b}\right)$. After the air spout border, there was an abrupt decrease in the air speed, with a maximum mean value of $7.56 \mathrm{~m} \mathrm{~s}^{-1} \mathrm{~cm}^{-1}$ in the case of the maximum test bench fan rotary speed.

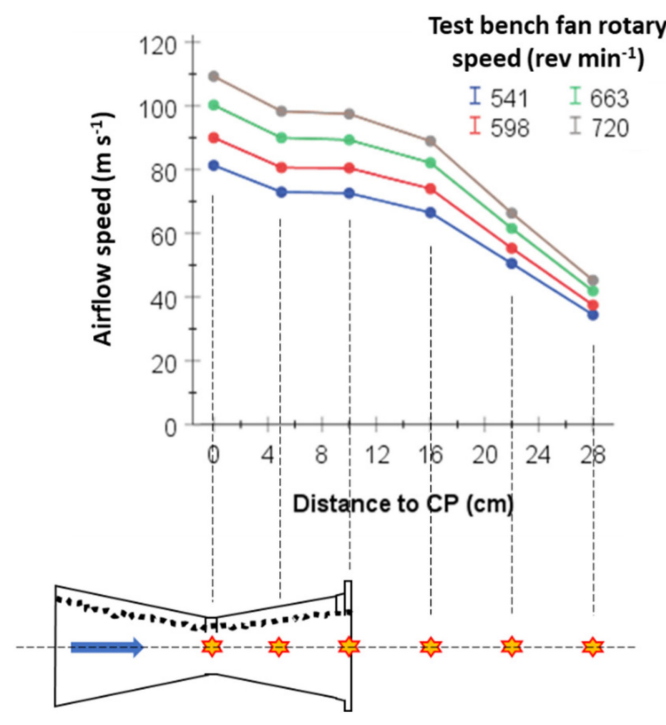

(a)

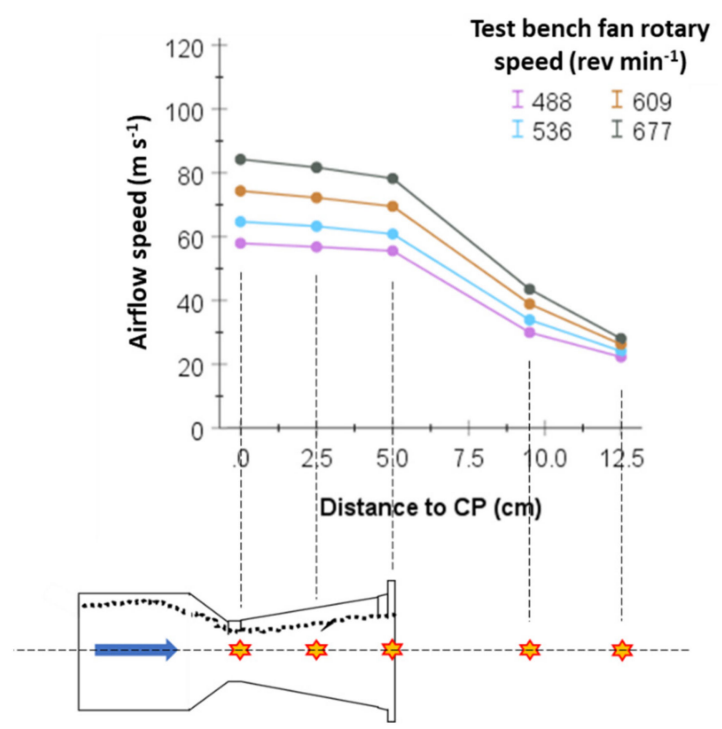

(b)

Figure 4. Airflow speed $\left(\mathrm{m} \mathrm{s}^{-1}\right)$ measured along the longitudinal axle of the spout at different distances $(\mathrm{cm})$ from the conventional position of liquid hose $(\mathrm{CP})$ at four test bench fan rotary speeds: (a) cannon-type and (b) hand-type pneumatic nozzles. Error bars show the \pm Standard Error of the Mean. 


\subsection{Droplets Size Spectra Measured}

The VMDs, or D50 values, distribution per liquid hose positions are shown separately by nozzle type in Figure 5. In general, the cannon (Figure 5a) generated finer droplets than the hand-type nozzle did (Figure 5b), with median values in their conventional insertion position of the liquid hose (CP) of 76 vs $95 \mu \mathrm{m}$, respectively. This fact is consistent with the observations made in previous droplet size characterization tests [53]. Nonetheless, there was a higher capacity to proportionally increase D50 values in the cannon ( $265 \%$ vs $223 \%$ total increase from CP to XP, Figure 5), which makes it possible to produce relatively similar drops in the XP in both the cannon- and hand-type nozzles (270 vs 307 $\mu \mathrm{m}$, Figure 5). When looking at the distribution of the D50 droplets in the different tested positions, values in the cannon spout were more homogeneously distributed than those in the hand spout. Thus, the first nozzle generated a D50 value of $74 \mu \mathrm{m}$ at the reference position $(\mathrm{CP})$, whereas values were 112,205 and $270 \mu \mathrm{m}$ at $\mathrm{AP}, \mathrm{OP}$ and XP positions, respectively. The last three values corresponded to $51 \%, 177 \%$ and $265 \%$ droplet diameter increase when compared to the reference position (CP). For the hand-shaped nozzle, a $95 \mu \mathrm{m}$ droplet diameter was recorded at CP. Diameters at AP (145 $\mu \mathrm{m})$, OP $(160$ $\mu \mathrm{m})$ and XP $(307 \mu \mathrm{m})$ were $53 \%, 68 \%$ and $223 \%$ larger, respectively, than those recorded at CP. As it can be seen (Figure 5), values were more heterogeneous in the hand-type nozzle (b) when compared to the cannon ones (a). The D50 variability (shown by the interquartile rate in Figure 5) in both nozzles increased with increasing distances from CP. This is also consistent with previous works characterizing pneumatic sprayer droplet size, as the droplet size indicators (D50 among them) can be predicted with linear models, which are affected by the liquid flow rate and air speed [53]. When comparing these global results with the air speed decrease rate (Figure 5), data were consistent in the cannon-type nozzle. Air speed decrease did not present extreme values along any of the measured sections, so a progressive droplet size increase was expected. On the other hand, the hand-type nozzle presented more extreme air speed decrease values, so the higher heterogeneity of data would be explained.

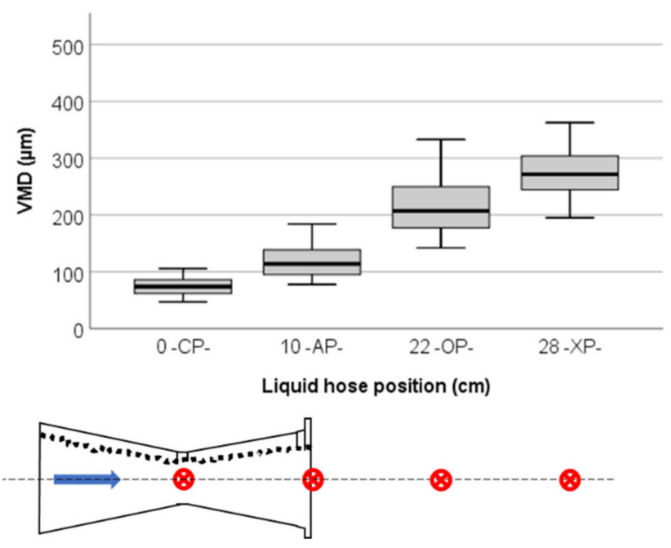

(a)

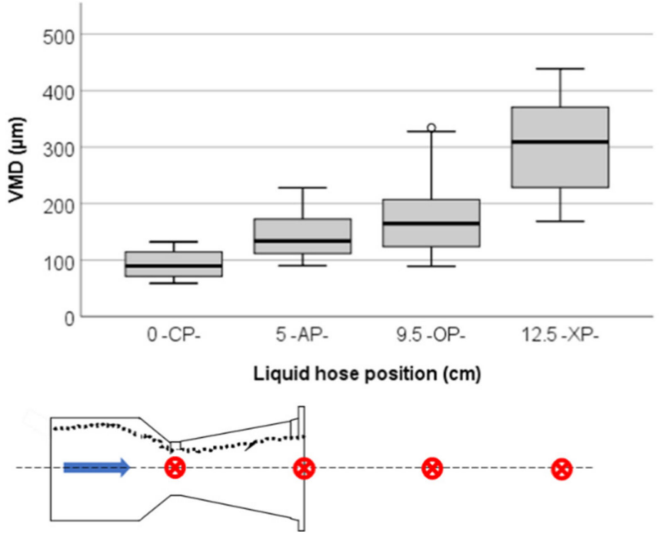

(b)

Figure 5. Volume Median Diameter (VMD) $(\mu \mathrm{m})$ per liquid hose position (HP): (a) cannon-type and (b) hand-type spouts. $\mathrm{CP}$, conventional insertion of liquid hose position; $\mathrm{AP}$, alternative position; $\mathrm{OP}$, out position; $\mathrm{XP}$, extreme position.

\subsubsection{Cannon-Type Nozzle}

D50, D10 and D90 values were significantly affected by the liquid hose position (HP), the LFR and the AS ( $p<0.001$, Figure 6a). In general, an increment in the droplet size can be observed for every indicator (D50, D10 and D90) with the increase of the liquid hose insertion distance to the original one. In this sense, moving the hose out of the spout generated an important increment in the droplet size, as expected by taking into account the air speed decrease found in the present work (Figure 4). This fact was also summarized in Figure 5a, where a clear increase in this parameter was found when increasing distance. As shown in previous works, air speed and liquid flow rate play key roles on 
droplet size $[53,55]$. Thus, the first parameter generates a clear decrease on the drop size and the second one behaves the opposite. Regarding D50, nearly every value obtained in the CP was lower than $100 \mu \mathrm{m}$ (Figure 6a). This contrasts with the case of the XP, where every value was above 200 $\mu \mathrm{m}$. AP and OP presented intermediate responses. Maximum and minimum D50 mean values were $325 \mu \mathrm{m}$ (with XP, minimum LFR and minimum AS) and $49 \mu \mathrm{m}$ (with CP, minimum LFR and maximum AS). In general, increments of D50 values were in the range 30\%-94\%: between 50\% and $75 \%$ moving the liquid hose position from $\mathrm{CP}$ to $\mathrm{AP}$, between $79 \%$ and $94 \%$ when the liquid hose was shifted from $\mathrm{AP}$ to $\mathrm{OP}$ and between $30 \%-43 \%$ when it was further moved to XP.

(a)

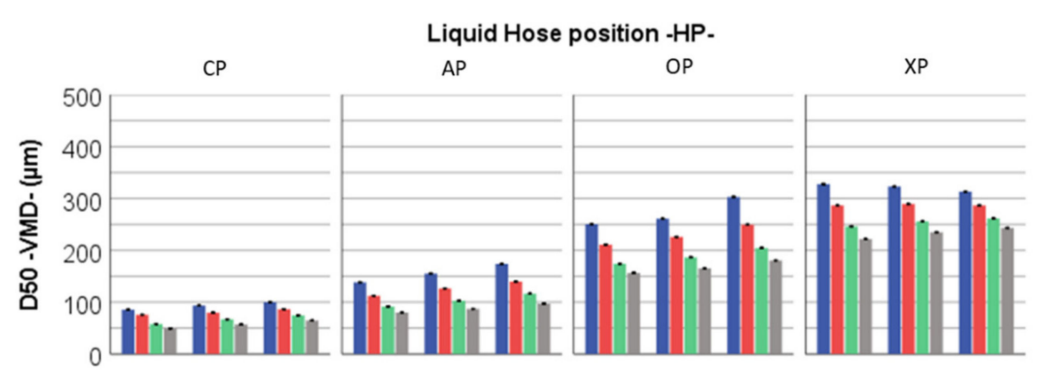

(b)

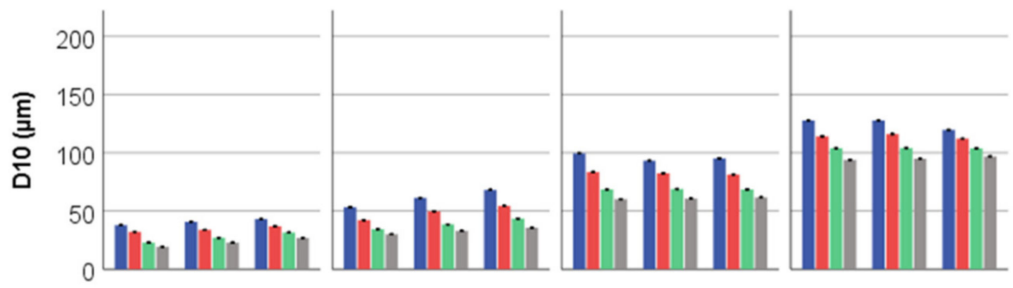

(c)

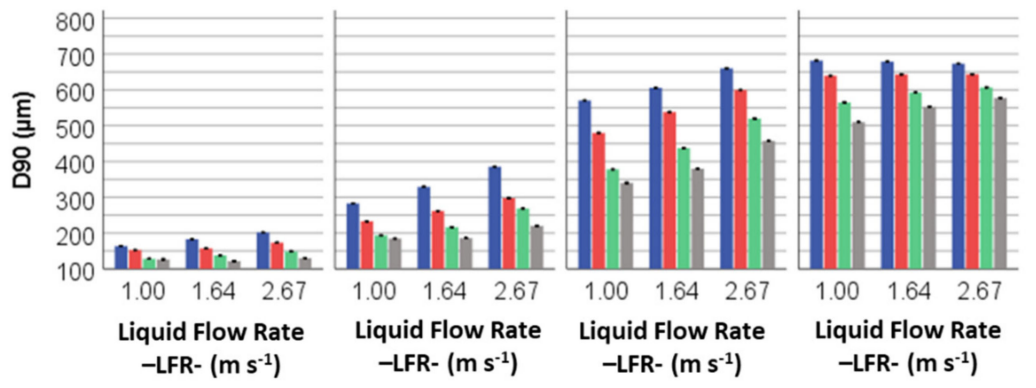

Airflow Speed-AS$\left(\mathrm{m} \mathrm{s}^{-1}\right)$

-81.3 100.2 $\square 90.0 \square 109.2$

Figure 6. (a) D50 (Volume Median Diameter, VMD), (b) D10 and (c) D90 values ( $\mu \mathrm{m})$ per liquid hose position (HP), liquid flow rate (LFR) and airflow speed (AS) for the cannon-type nozzle. Bars show the mean \pm Standard Error. $\mathrm{CP}$, conventional insertion of liquid hose position; $\mathrm{AP}$, alternative position; $\mathrm{OP}$, out position; $\mathrm{XP}$, extreme position.

D10 values for CP resulted below $45 \mu \mathrm{m}$ whilst the same values for XP were all above $90 \mu \mathrm{m}$ (Figure 6b). This fact has important practical implications because the use of pneumatic nozzle with the liquid hose in extreme position, allows to generate a very important fraction of the spray relatively safe from drifting, as it will be discussed in the V100 section. The maximum and minimum D10 mean values were $126 \mu \mathrm{m}$ (in XP combined with minimum LFR and minimum AS) and $17 \mu \mathrm{m}$ (in CP combined with minimum LFR and maximum AS; Figure 6b). The D10 mean increase from CP to AP ranged, in this case, from $36 \%$ to $80 \%$. The increase range between AP and OP was $52 \%$ to $89 \%$, whilst the same for OP to XP was $27 \%$ to $37 \%$. In this case, the atypical response of D10 decrease with the LFR increase was also found in the OP (Figure 6b).

D90 values comprised a minimum value of $128 \mu \mathrm{m}$ (in CP combined with minimum LFR and maximum AS) and a maximum of $682 \mu \mathrm{m}$ (in XP combined with minimum LFR and minimum AS; Figure $6 c$ ). The $C P$ resulted, in general, in values below $200 \mu \mathrm{m}$, whilst the XP yielded values above $500 \mu \mathrm{m}$. The mean D90 increase values were $73 \%$ from $\mathrm{CP}$ to $\mathrm{AP}, 101 \%$ from $\mathrm{AP}$ to OP and $18 \%$ from 
OP to XP. In the same way as D50 and D10, D90 values showed their highest heterogeneity in XP with relation to the rest of positions.

\subsubsection{Hand-Type Nozzle}

Similarly to the cannon-type nozzle, the three studied droplet size variables in the hand-type nozzle also depend on the HP, LFR and AS $(p<0.001)$. This fact is consistent with the air speed decrease found in the hand-type nozzle (Figure 4). General droplet size interval for every tested position can be observed in Figure 5b. Droplet size was more heterogeneous in the XP compared to that observed in the cannon spout.

The D50 values measured for the hand-type nozzle (Figure 7a) were slightly higher than those obtained in the cannon spout. Thus, CP resulted in D50 below $150 \mu \mathrm{m}$, with the minimum mean value of $62 \mu \mathrm{m}$ for the combination between minimum LFR and maximum AS. XP, on the other hand, resulted in D50 values above $125 \mu \mathrm{m}$, with a maximum value of $407 \mu \mathrm{m}$ for the combination of minimum LFR and minimum AS. In this particular case, the atypical behavior already observed for the cannon was also registered in the hand-type spout, with a decrease in the droplet size with the increase in the LFR. There was also a considerable influence of the other two evaluated parameters $\left(p<10^{-3}\right)$ on D50. In the case of LFR, there was a positive effect on D50, whilst the opposite was found for AS, as expected from previous works [53]. The mean D50 increase that can be found between CP and AP was $42 \%$. From AP to OP there was a mean increase of $39 \%$. Last, OP to XP had a mean VMD increment of $75 \%$.

(a)
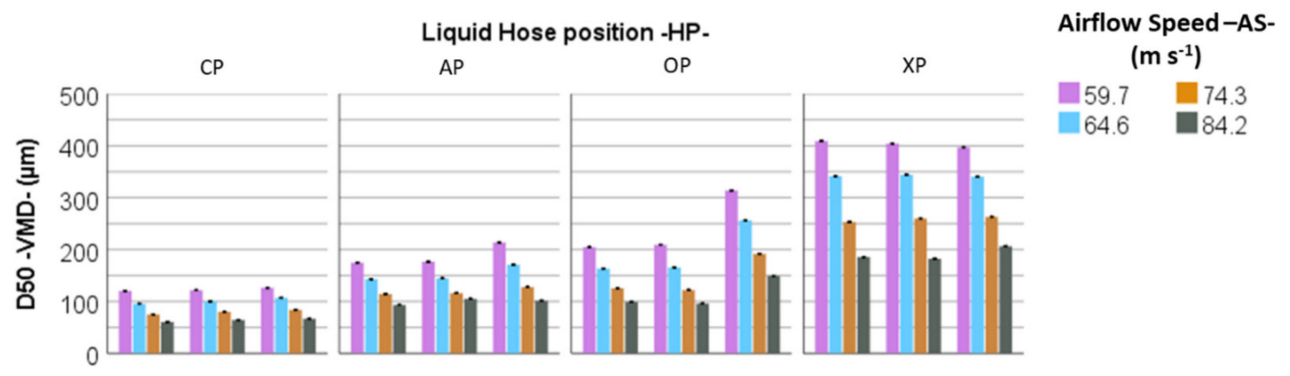

(b)

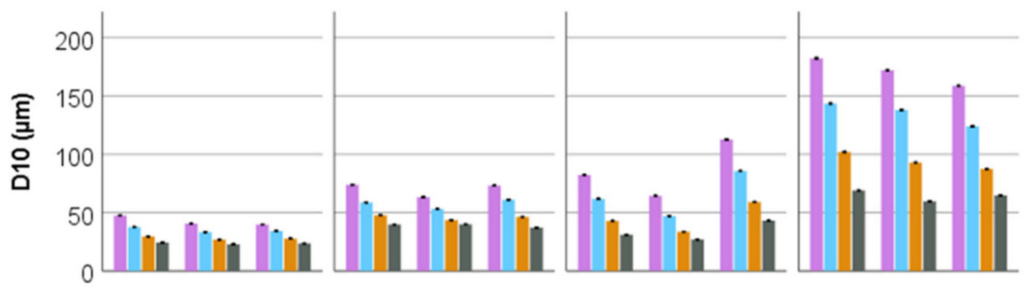

(c)

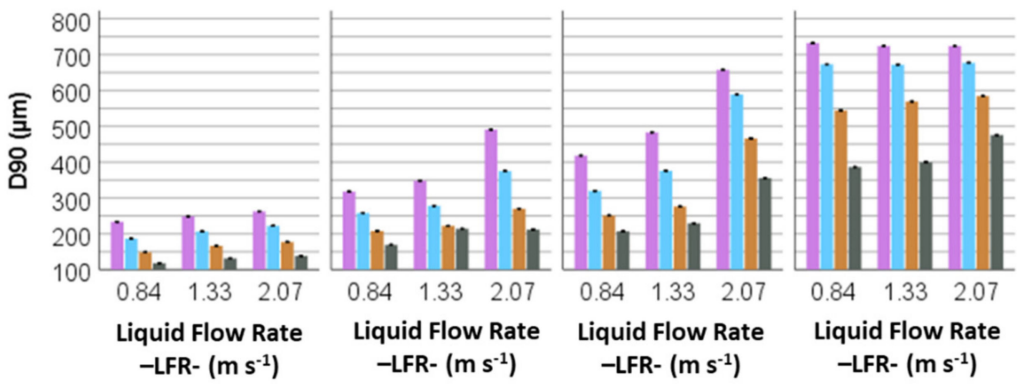

Figure 7. (a) D50 (Volume Median Diameter, VMD), (b) D10 and (c) D90 values ( $\mu \mathrm{m})$ per liquid hose position (HP), liquid flow rate (LFR) and airflow speed (AS) for the hand-type nozzle. Bars show the mean \pm Standard Error. CP, conventional insertion of liquid hose position; $\mathrm{AP}$, alternative position; $\mathrm{OP}$, out position; $\mathrm{XP}$, extreme position.

The D10 values (Figure $7 \mathrm{~b}$ ) comprised a minimum value of $23 \mu \mathrm{m}$ for the combination of $\mathrm{CP}$, intermediate LFR and maximum AS, and $179 \mu \mathrm{m}$ for the combination of $\mathrm{XP}$, minimum LFR and 
minimum AS. The CP presented D10 values all below $50 \mu \mathrm{m}$, while the XP presented values above $55 \mu \mathrm{m}$. The mean increase in this parameter from CP to AP was $49 \%$, from AP to OP it was $3 \%$ and from OP to XP it was $135 \%$.

The D90 values (Figure 7c) were all found below $280 \mu \mathrm{m}$ in CP and above $370 \mu \mathrm{m}$ in XP. The most extreme values were $112 \mu \mathrm{m}$ (for $\mathrm{CP} / \mathrm{min} \mathrm{LFR} / \max \mathrm{AS}$ ) and $735 \mu \mathrm{m}$ (for $\mathrm{XP} / \mathrm{min} \mathrm{LFR} / \mathrm{min} \mathrm{AS}$ ). The mean increase from $\mathrm{CP}$ to $\mathrm{AP}$ was $35 \%$, from $\mathrm{AP}$ to OP it was $28 \%$ and from OP to XP it was $94 \%$.

In general, it can be observed that the most extreme positions generated an atypical response of the LFR on the droplet size parameters. Nevertheless, the three LFR levels did not produce great differences in comparison with the AS ones. It could be stated that LFR had a lesser impact on droplet size in the outermost positions of the liquid hose.

\subsection{Cumulative Sprayed Volume Curves and Their Classification According to ASABE S572.1}

The cumulative sprayed volume curves, obtained with cannon (Figure 8) and hand-type (Figure 9) nozzles by testing all configurations (combination of HP, LFR and AS), compared with the American Society of Agricultural and Biological Engineers (ASABE) nozzles classifications (ASABE S572.1) [63], showed that an appropriate selection of pneumatic sprayer operational parameters, namely LFR and AS, led to a limited change in the spray quality generated, varying from very fine (VF) to fine (F) in the best cases. On the contrary, changing HP deeply affected the spray quality and reached the coarse (C) (Figure 8) and very coarse (VC) (Figure 9) spray quality when the liquid hose was tested in the extreme position (XP) combined with reduced AS, irrespective of LFR. Even if Balsari et al. [53] recognize the importance of a proper selection of LFR and AS parameters in order to vary the spray quality in conventional pneumatic sprayers, likewise it was clear that the spray quality extent change from VF to F was not enough to guarantee environmental safeguard, despite the increased droplet size dimension. For this reason, according to the preliminary tests performed by Miranda-Fuentes et al. [55], the HP change along the pneumatic spouts is proven as the driving factor for changing the spray quality. This strategy allows to achieve a range of different spray qualities comparable to that reachable with hydraulic nozzles, which can be varied in type (conventional vs air induction) and size [43]. Thus, at the time of application, in both pneumatic nozzle types the selection of HP allowed to vary the spray quality in a wide range without changing the other operational parameters selected for the application (LFR and AS). In detail, the cumulative sprayed volume curves derived from the tested configurations using the liquid hose in conventional position (CP) showed a droplet spectrum similar to the hydraulic nozzles Albuz ${ }^{\circledR}$ ATR lilac used at $0.7 \mathrm{MPa}$ (Figures 8 and 9) and selected as reference. Only the hand-type nozzle tested in CP position with AS of 59.7 and $64.6 \mathrm{~m} \mathrm{~s}^{-1}$ showed a coarser spray quality, namely fine (F), irrespective of LFR (Figure 9). On the contrary, none of the tested configurations with both cannon- and hand-type pneumatic nozzles in XP position achieved the extra coarse (XC) spray quality, likewise that generated by the air-induction Albuz ${ }^{\circledR}$ TVI8001 nozzles (0.7 MPa pressure) used as reference nozzle for the coarse spray quality (Figures 8 and 9). In general, the liquid hose position in AP and OP allowed intermediate spray quality, varying from $\mathrm{F}$ to $\mathrm{M}$ according to the LFR and AS selected. Even when the hand-type nozzle generated averagely larger droplets than the cannon-type did, the spray quality produced by both of them, for the same tested configuration, was very similar (Figures 8 and 9). In practice, no substantial difference in prospective coverage of the leaves and fruits could be noticed between the two nozzle types. In any case, the possibility to vary in a wide range the droplet size by simply adjusting the liquid hose position gives, for the first time, the opportunity to both farmers and technicians to match the environmental requirements, balancing at the same time the treatment specifications for every spray application while using pneumatic spraying in vineyards. Recently, Grella et al. [58] demonstrated through field trials that the variation in the spray quality over the range investigated (from $\mathrm{CP}$ to $\mathrm{XP}$ ) did not affect the canopy coverage, while coarser sprays (liquid hose in $\mathrm{AP}$ and $\mathrm{XP}$ ) produced greater deposits on the target. Concurrently, the use of cannon spout in $\mathrm{XP}$ position significantly reduced the off-field ground losses in the downwind area. 


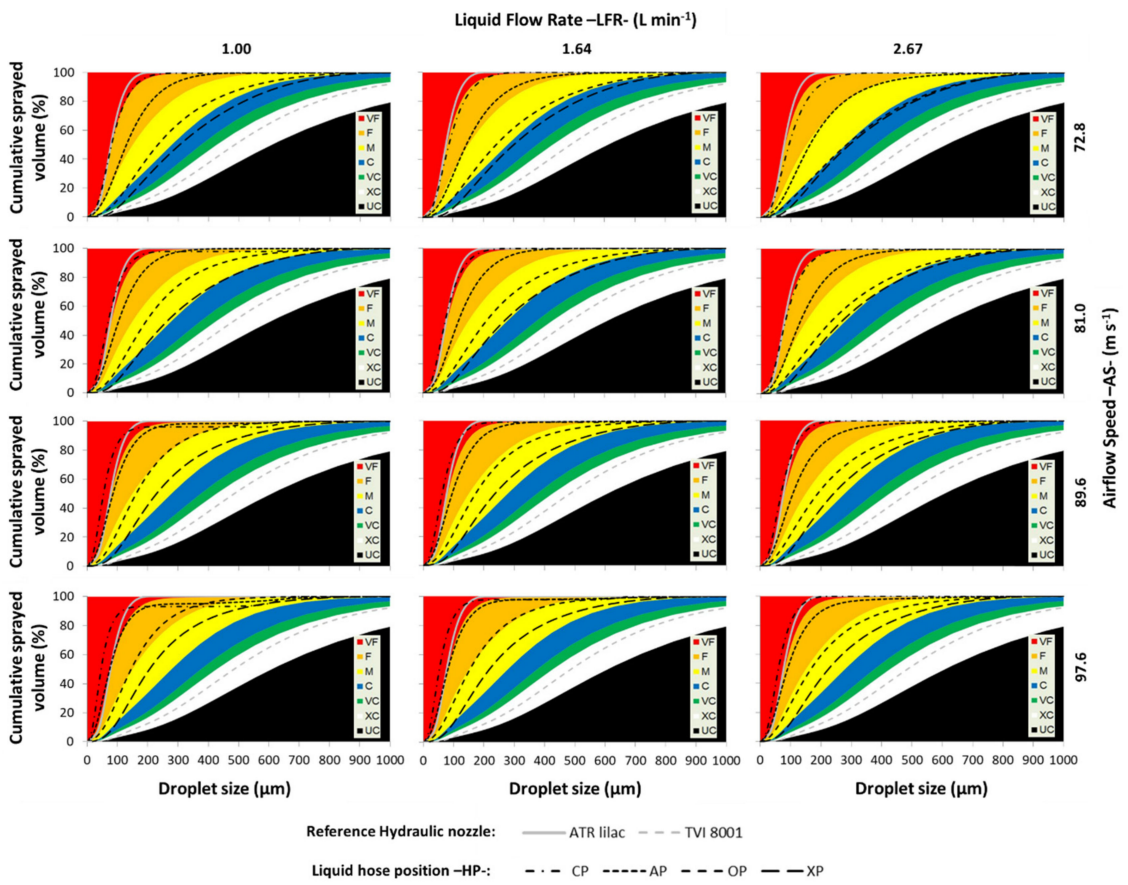

Figure 8. Cumulate sprayed volume (\%) curves as a function of droplet size $(\mu \mathrm{m})$ per liquid flow rate (LFR), airflow speed (AS) and liquid hose position (HP) for the cannon-type nozzle. In each graph the hydraulic reference nozzles hollow cone conventional ATR lilac and air-induction TVI 8001 (Albuz ${ }^{\circledR}$ ) are displayed, both operated at $0.7 \mathrm{MPa}$ pressure. $\mathrm{CP}$, conventional insertion of liquid hose position; $\mathrm{AP}$, alternative position; $\mathrm{OP}$, out position; $\mathrm{XP}$, extreme position. VF, very fine; $\mathrm{F}$, fine; $\mathrm{M}$, medium; $\mathrm{C}$, coarse; VC, very coarse; $\mathrm{XC}$, extremely coarse; UC, ultra-coarse/unclassified; (ASABE S572.1).

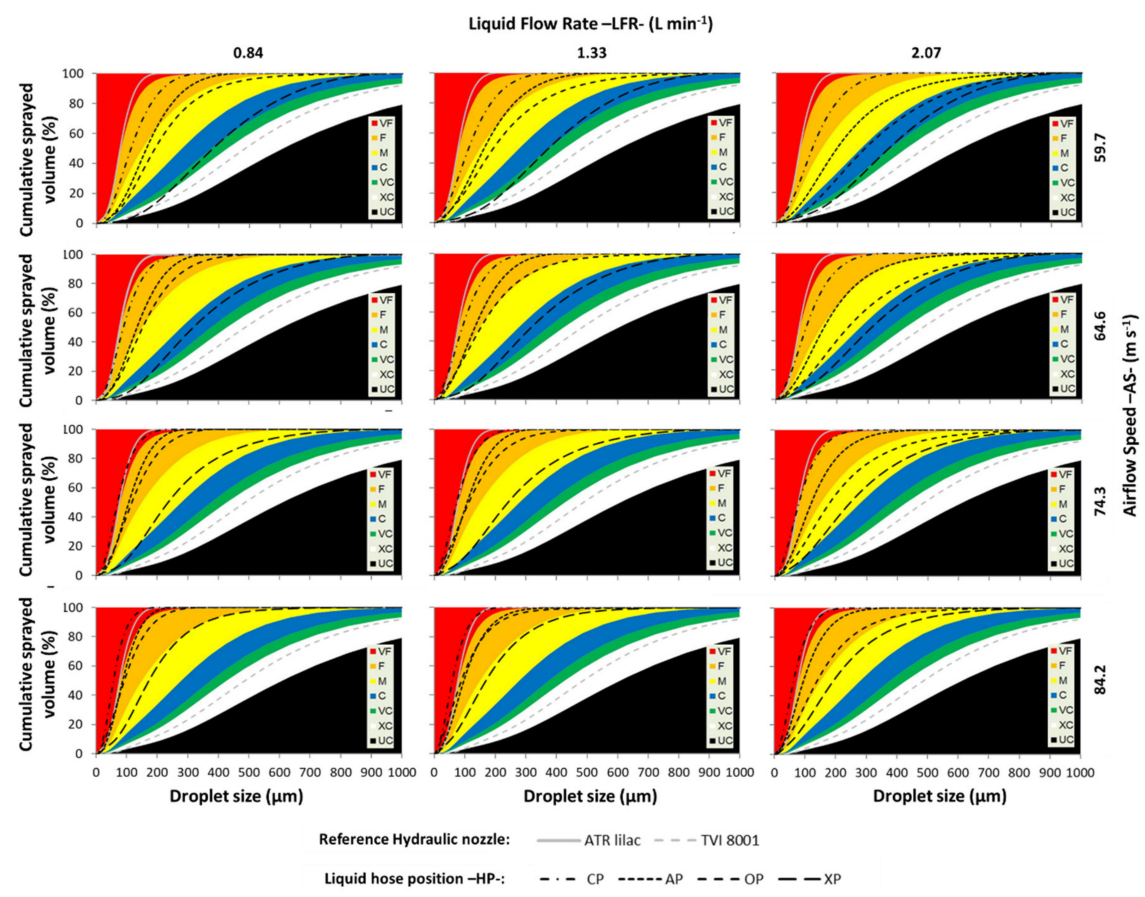

Figure 9. Cumulate sprayed volume $(\%)$ curves as a function of droplet size $(\mu \mathrm{m})$ per liquid flow rate (LFR), airflow speed (AS) and liquid hose position (HP) for the hand-type nozzle. In each graph the hydraulic reference nozzles hollow cone conventional ATR lilac and air-induction TVI 8001 (Albuz ${ }^{\circledR}$ ) are displayed, both operated at $0.7 \mathrm{MPa}$ pressure. $\mathrm{CP}$, conventional insertion of liquid hose position; $\mathrm{AP}$, alternative position; $\mathrm{OP}$, out position; $\mathrm{XP}$, extreme position. VF, very fine; $\mathrm{F}$, fine; $\mathrm{M}$, medium; $\mathrm{C}$, coarse; VC, very coarse; $X C$, extremely coarse; UC, ultra-coarse/unclassified; (ASABE S572.1). 


\subsection{Droplet Homogeneity}

Significant differences $(p<0.001)$ were found in both nozzles for every single variable and their interactions. In general, it could be stated that the distance increase to the $\mathrm{CP}$ generates an increase in the droplet heterogeneity (Figure 10). This result is in line with the results obtained in previous works for the CP and the AP [55]. RSF values were slightly lower in the hand spout than in the cannon one (1.63 vs 1.78$)$, especially in the surroundings of the $C P$.

In the cannon spout, the hose position change, although statistically significant, did not generate major differences in the mean RSF values (Figure 10a). Thus, values for every single position were near 2.00. The observed trend was a reduction in the droplet population homogeneity with the distance increase from the CP. The increase in AS also increased the RSF in general, especially in the case of the lower LFR in the CP (Figure 10a).

There was a much higher influence of the hose insertion position in the case of the hand spout (Figure 10b). In this case all values were around 2.00, but with important differences among the tested hose positions. There was a significant particularity in the hand spout case: values presented a higher RSF in the OP than in the XP, while the opposite would have been the most predictable scenario (Figure 10b). It should be pointed out that in this nozzle both LFR and AS had a higher impact on the RSF than they had in the cannon spout.

(a)

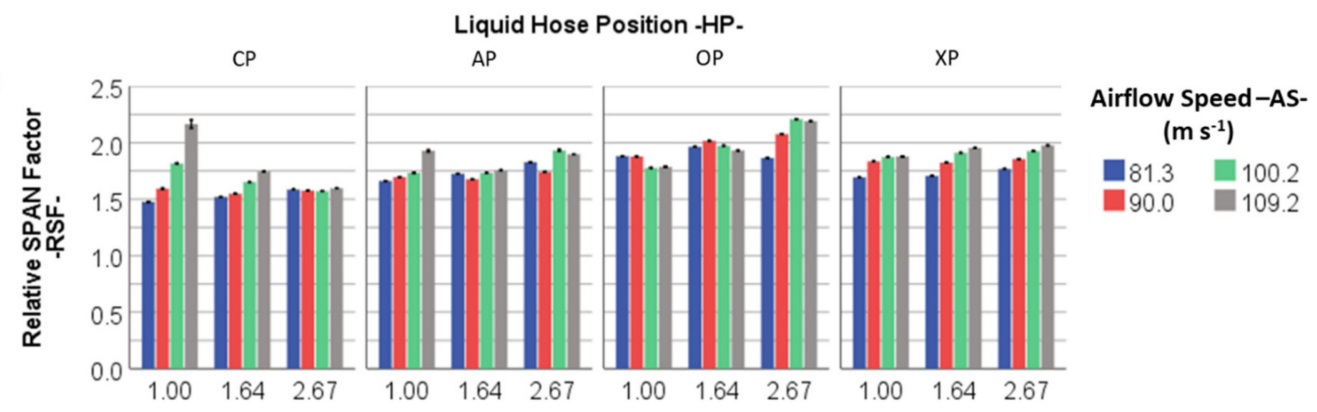

(b)

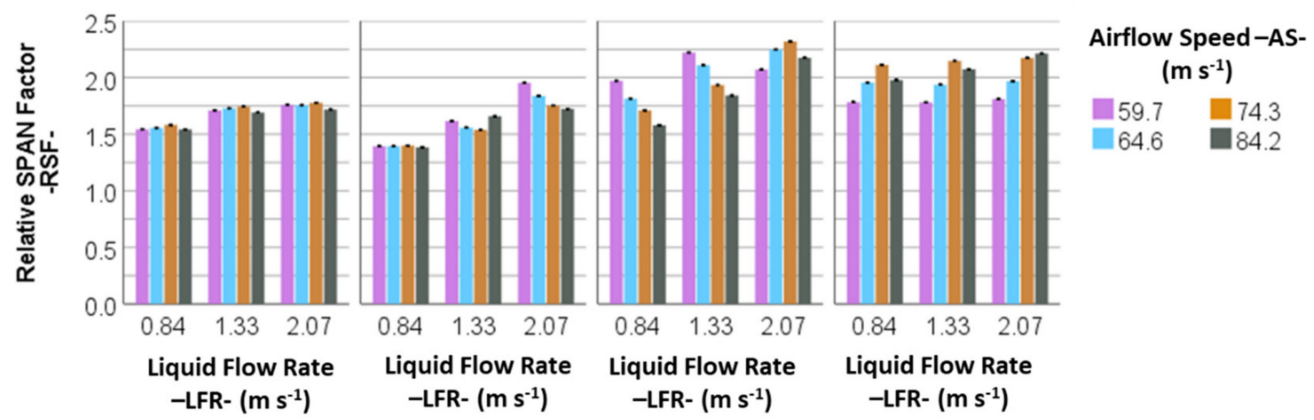

Figure 10. Relative SPAN Factor (RSF) per liquid hose position (HP), liquid flow rate (LFR) and airflow speed (AS) for both the (a) cannon-type and (b) hand-type nozzles. Bars show the mean \pm Standard Error. $\mathrm{CP}$, conventional insertion of liquid hose position; $\mathrm{AP}$, alternative position; $\mathrm{OP}$, out position; $\mathrm{XP}$, extreme position.

The comparison between both nozzles regarding the droplet homogeneity follows a trend similar to that observed in previous works [53]. In those, a positive influence of both LFR and AS was observed on the RSF in both nozzles. Similarly to the present findings, the cannon spout had a higher RSF than the hand-type one did. A marked increase in the droplet heterogeneity was also observed in the maximum AS and minimum LFR combination (Figure 10a). This could be explained by the fact that with a very low LFR the amount of sprayed liquid might be insufficient for the high air current to produce an optimal water division into homogeneous droplets, thus increasing the amount of very fine ones, altering their normal distribution and increasing the droplets heterogeneity by affecting the kurtosis. 


\subsection{Droplet Driftability}

According to other authors $[13,43,56,57,64]$, the V100 is a valuable parameter to predict spray drift. The lower this parameter, the lower the portion of spray droplets below $100 \mu \mathrm{m}$ and, therefore, the predicted incidence of the spray drift. As it is displayed in Figure 11, V100 values were generally higher for the cannon-type nozzle in the $\mathrm{CP}$ and AP. This trend enhanced the spray drift generation during field spray application, as the cannon spout must spray at a longer distance from the target than the hand one in the conventional setting used in farms (Figure 1b). Nevertheless, the present study showed a different behavior of the two nozzle types in the droplet size spectra increase after the AP (liquid hose out of the spout body). Thus, for OP and XP, cannon spout presented lower V100 values when compared to the hand-type one (Figure 11). This finding might be relevant for the spray drift reduction, as it could indicate a higher interest in implementing OP and XP in the cannon spout.

(a)

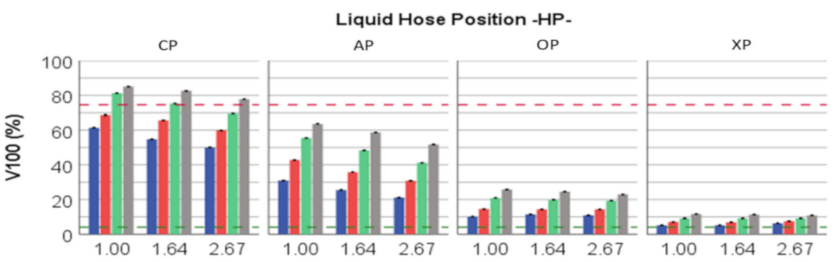

(b)

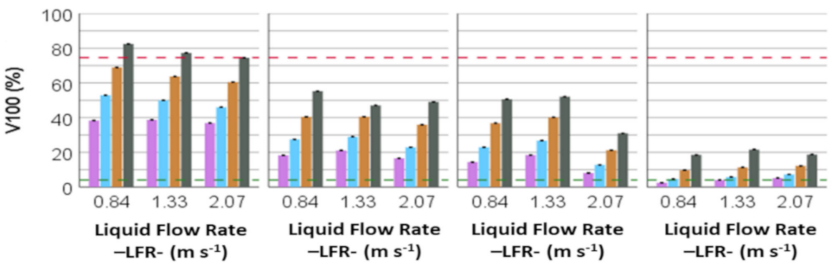

Airflow Speed-AS-

$\left(\mathrm{m} \mathrm{s}^{-1}\right)$

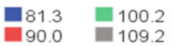

Airflow Speed-AS-

$\left(\mathrm{m} \mathrm{s}^{-1}\right)$

$\begin{array}{ll}59.7 & \mathbf{E} \\ 64.6 & 74.3 \\ 64.2\end{array}$

Figure 11. V100 (\%) per liquid hose position (HP), liquid flow rate (LFR) and airflow speed (AS) for both the (a) cannon-type and (b) hand-type nozzles. Bars show the mean \pm Standard Error. The dashed lines represent the hydraulic reference nozzles, namely hollow cone conventional ATR lilac in red and air induction TVI 8001 in green (Albuz ${ }^{\circledR}$ ), both operated at $0.7 \mathrm{MPa}$ pressure. $\mathrm{CP}$, conventional insertion of liquid hose position; $\mathrm{AP}$, alternative position; $\mathrm{OP}$, out position; $\mathrm{XP}$, extreme position.

Indeed, in the case of the cannon-type nozzle, there was a consistent V100 reduction among consecutive hose positions. Thus, from a mean value of $68 \%$ in $\mathrm{CP}$, the V100 mean value decreased to $8 \%$ in XP (Figure 11a). Within each liquid hose position, the combination of minimum LFR with maximum AS and maximum LFR with minimum AS deeply affected the driftability. These settings yielded mean V100 values of $49 \pm 2 \%(\max \mathrm{LFR} / \mathrm{min} \mathrm{AS})$ and $61 \pm 2 \%(\min \mathrm{LFR} / \mathrm{max} \mathrm{AS})$ in CP (Figure 10a). AP gave V100 results between $21 \pm 1 \%(\max \mathrm{LFR} / \mathrm{min} \mathrm{AS})$ and $64 \pm 2 \%(\mathrm{~min} \mathrm{LFR} / \mathrm{max}$ AS). OP resulted in a range from $10 \pm 1 \%$ (max LFR/ min AS) to $21 \pm 1 \%$ (min LFR/max AS). Finally, $\mathrm{XP}$ values ranged from $5 \pm 1 \%$ (min LFR/ min AS) to $10 \pm 1 \%$ (min LFR/max AS) (Figure 10a). In a practical way, the best V100 reduction within each hose position was always achieved when the system was operated with the maximum LFR and minimum AS, confirming the marked influence of these operational parameters [53].

Comparing V100 values generated by pneumatic nozzles with those generated by the reference hydraulic nozzle (Figure 11a) Albuz ${ }^{\circledR}$ ATR lilac operated at $0.7 \mathrm{MPa}$ pressure (dashed red line corresponding to V100 equal to $74 \%$ ), it can be observed that similar values were obtained when the pneumatic nozzles were used in CP and combined with the highest AS $\left(89.6\right.$ and $\left.97.7 \mathrm{~m} \mathrm{~s}^{-1}\right)$. Changing the hose position from AP to $\mathrm{XP}$, all possible combinations of tested parameters reduced the V100 level compared with the reference nozzle. This finding reflects the capability of AP, OP and $\mathrm{XP}$ to generate droplet populations with a driftability similar to those produced by a wide range of conventional hydraulic nozzles characterized by different dimensions and operated in a wide range of liquid pressure. Specifically, the V100 values for XP were similar to those obtained using hydraulic air induction nozzles. Indeed, the cannon-type nozzle operated in the XP position and, combined with 
the lowest AS, achieved V100 values fully comparable with those obtained with air induction nozzle Albuz $^{\circledR}$ TVI8001 (V100 equal to 4\%) marked with the dashed green line in Figure 11a. The minimum value achieved in the XP was 5\%, so the droplet size can be considered similar to that of a conventional low-drift nozzle. Considering the configurations characterized by the combination of highest AS (97.6 $\mathrm{m} \mathrm{s}^{-1}$ ) and highest LFR (2.67 L min $\left.{ }^{-1}\right)$, the switch of HP from CP to XP determined a reduction of V100 equal to $90 \%$, a value fully confirmed by field trials that showed a $95 \%$ reduction in off-target losses [58].

Regarding the hand-type spout, there was a significant reduction in V100 across the different hose positions, turning from a mean value of $58 \%$ in CP to $9 \%$ in XP (Figure 11b). Nevertheless, there was a low reduction between AP and OP. Indeed, the mean V100 value only decreased from $29 \%$ to $28 \%$. The lowest possible value in the conventional nozzle configuration was $37 \pm 1 \%$ for the maximum LFR with the minimum AS (Figure 11b). AP originated values between a maximum mean value of $53 \pm 3 \%$ (med LFR/max AS) and a minimum of $8 \pm 2 \%$. OP yielded values between $56 \pm 1 \%$ (min LFR/max AS) and $16 \pm 1 \%$ (max LFR/min AS). Finally, XP resulted in values from $22 \pm 1 \%$ (med LFR/max AS) and $3 \pm 1 \%$ (min LFR/min AS) (Figure 11b). Comparing these values with the reference nozzle Albuz ${ }^{\circledR}$ ATR lilac operated at 0.7 MPa pressure (V100 equal to 74\%), only the liquid hose in CP combined with the highest AS generated values higher than the threshold marked with a dashed red line in Figure 11b. Concurrently, the liquid hose in XP combined with the lowest AS was able to lower the V100 threshold fixed by the reference air induction nozzle Albuz ${ }^{\circledR}$ TVI8001 marked with the dashed green line in Figure 11b. The very low V100 values achieved in the last position of the liquid hose were even lower than many of the ones reported for the hydraulic low-drift nozzles [43]. Even if the V100 values measured in this study $(74 \%)$ for the Albuz ${ }^{\circledR}$ ATR lilac operated at 0.7 MPa pressure were higher than those obtained by Zande et al. [43] (equal to 23\%), the droplet size spectra parameters were fully in accordance with those reported by ASABE S572.1 classification, and the nozzle falls in the same class, namely very fine (VF) [63].

As it can be drawn from Figure 12, there was a clear correlation between V100 and D50 in both cases $(p<0.001)$. Determination coefficients were very similar $(0.9764$ and 0.9704 in the cannon-type (Figure 12a) and hand-type (Figure 12b) nozzles), and the correlation coefficients were nearly the same $(-0.01$ and -0.009$)$. This result indicates that both nozzles have similar behavior. Moreover, this kind of response can be expected from different pneumatic nozzles. In the case of the cannon, there was a deviation of the regression line with high D50 values. This behavior can be expected when taking into account the higher variability that is found in the most extreme positions of the liquid hose (Figure 12a). A similar trend can be noticed in the hand nozzle for which a loss of fitting in the lowest D50 values can be observed (Figure 12b).

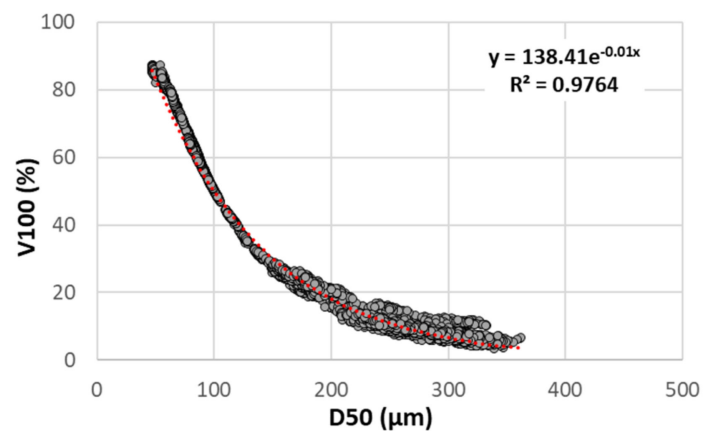

(a)

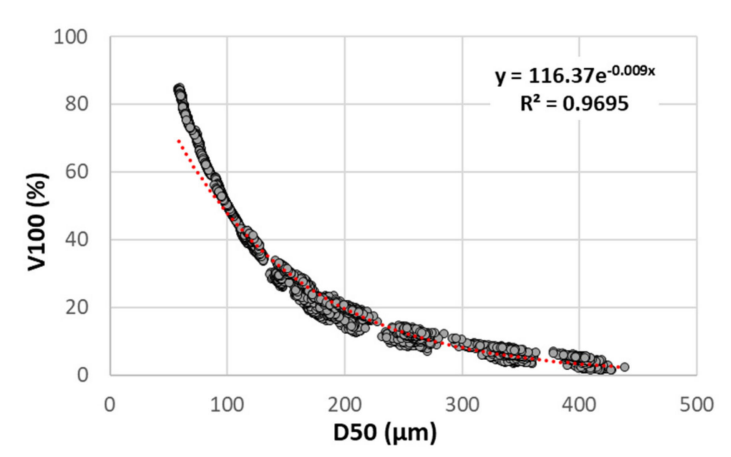

(b)

Figure 12. Correlation between D50 $(\mu \mathrm{m})$ and V100 (\%) for all tested configurations (combination of liquid hose insertion position (HP), liquid flow rate (LFR) and air speed (AS) for both the (a) cannon-type and (b) hand-type nozzles. 


\section{Conclusions}

Following previous findings related to the droplet size increase in pneumatic spraying, a study was carried out to check the influence of modifications in the liquid hose position with respect to the air spout. In both tested nozzles, namely cannon and hand types, the air speed decreased consistently from the inner to the outer part of the spout, with higher decrease outside of the spout.

Therefore, the strategy to move the liquid release hose to outer positions with respect to the conventional one is as an effective way to substantially increase the droplet size spectra generated by pneumatic sprayers. This effect was certified by the Volume Median Diameter (D50) increase equal to $280 \%$ for the cannon and $270 \%$ for the hand spouts just by changing the liquid hose position from the inner to the outermost spout position. Similar results were obtained for D10 and D90. In particular, the variation of liquid hose position from conventional to extreme out of spout position (XP) allowed to vary the spray quality generated from very fine $(\mathrm{VF})$ to coarse $(\mathrm{C})$ /very coarse $(\mathrm{VC})$, giving farmers a wide range of options during the spray application. The droplet driftability, measured by the V100 parameter, decreased with the increase of the liquid hose distance from its original position. This suggests that when the liquid hose is in the extreme outer position, the pneumatic nozzle behaves similarly to a hydraulic drift reducing nozzle.

The findings of this study could significantly help in reducing the spray drift in pneumatic spraying just by slightly modifying the spray nozzle, which could have important practical implications. For the first time it is possible to design a device that gives farmers and technicians the possibility to match the drift-reduction environmental requirements using pneumatic sprayers for 3D crops, balancing at the same time the treatment specifications for every spray application.

Author Contributions: Conceptualization, M.G., A.M.F., P.M. and P.B.; methodology, M.G., A.F.M., P.M. and P.B.; validation, M.G., A.F.M. and P.M.; formal analysis, M.G. and A.F.M.; investigation, M.G., A.F.M., P.M. and F.G; resources, P.B.; data curation, M.G. and A.F.M.; writing-original draft preparation, M.G. and A.F.M.; writing-review and editing, M.G., A.F.M., P.M., P.B and F.G.; visualization, M.G.; supervision, M.G., P.B. and F.G.; project administration, F.G.; funding acquisition, P.B.; All authors have read and agreed to the published version of the manuscript.

Funding: This research received no external funding.

Acknowledgments: The authors would like to thank CIMA S.p.a. (Pavia, IT) for providing the spouts used in the experimental work.

Conflicts of Interest: The authors declare no conflict of interest.

\section{Abbreviations}

AS

AP

$\mathrm{CP}$

D10

D50

D90

HP

LFR

OP

RSF

V100

VMD

XP

Air speed

Alternative insertion position of the liquid hose in the spout

Conventional insertion position of the liquid hose in the spout

Diameter for which a volume fraction of $10 \%$ is made up of drops

with diameters smaller than this value (expressed in $\mu \mathrm{m}$ )

Diameter for which a volume fraction of $50 \%$ is made up of drops

with diameters smaller than this value (expressed in $\mu \mathrm{m}$ )

Diameter for which a volume fraction of $90 \%$ is made up of drops

with diameters smaller than this value (expressed in $\mu \mathrm{m}$ )

Liquid hose position

Liquid flow rate in the spraying circuit

Insertion position of the liquid hose out of the spout

Relative SPAN factor, a measure of the droplet homogeneity in the spray population (dimensionless)

Spray liquid fraction generated with droplets smaller than $100 \mu \mathrm{m}$ (expressed in \%)

Volumetric median diameter, equivalent to D50

Insertion position of the liquid hose at the extreme distance out of the spout 


\section{References}

1. International Organization of Vine and Wine. OIV Statistical Report on World Vitiviniculture. 2018. Available online: http://www.oiv.int/public/medias/6371/oiv-statistical-report-on-world-vitiviniculture-2018. pdf (accessed on 7 September 2020).

2. Goodell, P.B. Fifty years of integrated control concept: The role of landscape ecology in IPM in San Joaquin valley cotton. Pest Manag. Sci. 2009, 65, 1293-1297. [CrossRef] [PubMed]

3. Gil, E.; Escolà, A. Design of a decision support method to determine volume rate for vineyard spraying. Appl. Eng. Agric. 2009, 25, 145-152. [CrossRef]

4. EC. Directive 2009/128/EC of the European Parliament and the Council of 21 October 2009 Establishing a Framework for Community Action to Achieve the Sustainable use of Pesticides. Off. J. Eur. Union L 2009, 309, 71-86.

5. Cerruto, E.; Manetto, G.; Longo, D.; Failla, S.; Papa, R. A model to estimate the spray deposit by simulated water sensitive papers. Crop. Prot. 2019, 124, 104861. [CrossRef]

6. Cross, J.V.; Walklate, P.J.; Murray, R.A.; Richardson, G.M. Spray deposits and losses in different sized apple trees from an axial fan orchard sprayer: 1. Effects of spray liquid flow rate. Crop. Prot. 2001, 20, 13-30. [CrossRef]

7. Cross, J.V.; Walklate, P.J.; Murray, R.A.; Richardson, G.M. Spray deposits and losses in different sized apple trees from an axial fan orchard sprayer: 2. Effects of spray quality. Crop. Prot. 2001, 20, 333-343. [CrossRef]

8. Cross, J.V.; Walklate, P.; Murray, R.; Richardson, G. Spray deposits and losses in different sized apple trees from an axial fan orchard sprayer: 3. Effects of air volumetric flow rate. Crop. Prot. 2003, 22, 381-394. [CrossRef]

9. Failla, S.; Romano, E.; Longo, D.; Bisaglia, C.; Schillaci, G. Effect of different axial fans configurations on airflow rate. In Innovative Biosystems Engineering for Sustainable Agriculture, Forestry and Food Production, Proceedings of the MID-TERM AIIA, Matera, Italy, 12-13 September; Coppola, A., Di Renzo, G., Altieri, G., D'Antonio, P., Eds.; Springer: Cham, Switzerland, 2020; Volume 67, pp. 691-699. [CrossRef]

10. Hołownicki, R.; Doruchowski, G.; Świechowski, W.; Godyń, A.; Konopacki, P.J. Variable air assistance system for orchard sprayers; concept, design and preliminary testing. Biosyst. Eng. 2017, 163, 134-149. [CrossRef]

11. Longo, D.; Manetto, G.; Papa, R.; Cerruto, E. Design and construction of a low-cost test bench for testing agricultural spray nozzles. Appl. Sci. 2020, 10, 5221. [CrossRef]

12. Nuyttens, D.; Baetens, K.; de Schampheleire, M.; Sonck, B. Effect of nozzle type, size and pressure on spray droplet characteristics. Biosyst. Eng. 2007, 97, 333-345. [CrossRef]

13. Salcedo, R.; Vallet, A.; Granell, R.; Garcerá, C.; Moltó, E.; Chueca, P. Eulerian-Lagrangian model of the behaviour of droplets produced by an air-assisted sprayer in a citrus orchard. Biosyst. Eng. 2017, 154, 76-91. [CrossRef]

14. Świechowski, W.; Doruchowski, G.; Holownicki, R.; Godyn, A. Penetration of air within the apple tree canopy as affected by the air jet characteristics and travel velocity of the sprayer. Electron. J. Pol. Agric. Univ. 2004, 7, \#03.

15. Celen, I.H.; Arin, S.; Durgut, M.R. The effect of the air blast sprayer speed on the chemical distribution in vineyard. Pak. J. Biol. Sci. 2008, 11, 1472-1476. [CrossRef]

16. Cerruto, E. Influence of airflow rate and forward speed on the spray deposit in vineyards. J. Agric. Eng. 2007, 1, 7-14.

17. Duga, A.T.; Ruysen, K.; Dekeyser, D.; Nuyttens, D.; Bylemans, D.; Nicolaï, B.M.; Verboven, P. Spray deposition profiles in pome fruit trees: Effects of sprayer design, training system and tree canopy characteristics. Crop. Prot. 2015, 67, 200-213. [CrossRef]

18. ISO. ISO22866:2005: Equipment for Crop Protection-Methods for Field Measurements of Spray Drift; International Organization for Standardization: Geneva, Switzerland, 2005; pp. 1-17.

19. Arvidsson, T.; Bergström, L.; Kreuger, J. Spray drift as influenced by meteorological and technical factors. Pest Manag. Sci. 2011, 67, 586-598. [CrossRef]

20. Garcerá, C.; Moltó, E.; Chueca, P. Spray pesticide applications in Mediterranean citrus orchards: Canopy deposition and off-target losses. Sci. Total Environ. 2017, 599, 1344-1362. [CrossRef] 
21. Gil, E.; Llorens, J.; Gallart, M.; Gil-Ribes, J.A.; Miranda-Fuentes, A. First attempts to obtain a reference drift curve for traditional olive grove's plantations following ISO 22866. Sci. Total Environ. 2018, 627, 349-360. [CrossRef] [PubMed]

22. Gil, E.; Llorens, J.; Llop, J.; Fàbregas, X.; Gallart, M. Use of a terrestrial LIDAR sensor for drift detection in vineyard spraying. Sensors 2013, 13, 516-534. [CrossRef]

23. Grella, M.; Gallart, M.; Marucco, P.; Balsari, P.; Gil, E. Ground deposition and airborne spray drift assessment in vineyard and orchard: The influence of environmental variables and sprayer settings. Sustainability 2017, 9, 728. [CrossRef]

24. Grella, M.; Marucco, P.; Balafoutis, A.T.; Balsari, P. Spray drift generated in vineyard during under-row weed control and suckering: Evaluation of direct and indirect drift-reducing techniques. Sustainability 2020, 12, 5068. [CrossRef]

25. Grella, M.; Marucco, P.; Manzone, M.; Gallart, M.; Balsari, P. Effect of sprayer settings on spray drift during pesticide application in poplar plantations (Populus spp.). Sci. Total Environ. 2017, 578, 427-439. [CrossRef]

26. Praat, J.P.; Maber, J.F.; Manktelow, D.W.L. The effect of canopy development and sprayer position on spray drift from a pipfruit orchard. N. Z. Plant Prot. 2000, 53, 241-247. [CrossRef]

27. Salyani, M.; Farooq, M.; Sweeb, R.D. Spray deposition and mass balance in citrus orchard applications. Trans. $A S A B E$ 2007, 50, 1963-1969. [CrossRef]

28. Felsot, A.S.; Unsworth, J.B.; Linders, J.B.H.J.; Roberts, G. Agrochemical spray drift; assessment and mitigation-A review. J. Environ. Sci. Health B 2011, 46, 1-23. [CrossRef]

29. Balsari, P.; Marucco, P.; Tamagnone, M. A system to assess the mass balance of spray applied to tree crops. Trans. ASAE 2005, 48, 1689-1694. [CrossRef]

30. Derksen, R.C.; Zhu, H.; Fox, R.D.; Brazee, R.D.; Krause, C.R. Coverage and drift produced by air induction and conventional hydraulic nozzles used for orchard applications. Trans. ASABE 2007, 50, 1493-1501. [CrossRef]

31. Bonds, J.A.S.; Leggett, M. A Literature Review of Downwind Drift from Airblast Sprayers: Development of Standard Methodologies and a Drift Database. Trans. ASABE 2015, 58, 1471-1477.

32. Fox, R.D.; Derksen, R.C.; Zhu, H.; Brazee, R.D.; Svensson, S.A. A history of air-blast sprayer development and future prospects. Trans. ASABE 2008, 51, 405-410. [CrossRef]

33. Gil, Y.; Sinfort, C. Emission of pesticides to the air during sprayer application: A bibliographic review. Atmos. Environ. 2005, 39, 5183-5193. [CrossRef]

34. Hewitt, A.J. Droplet size and agricultural spraying, part I: Atomization, spray transport, deposition, drift, and droplet size measurement techniques. At. Sprays 1997, 7, 235-244. [CrossRef]

35. Lešnik, M.; Pintar, C.; Lobnik, A.; Kolar, M. Comparison of the effectiveness of standard and drift-reducing nozzles for control of some pests of apple. Crop. Prot. 2005, 24, 93-100. [CrossRef]

36. Miranda-Fuentes, A.; Rodríguez-Lizana, A.; Cuenca, A.; González-Sánchez, J.; Blanco-Roldán, G.L.; Gil-Ribes, J.A. Improving plant protection product applications in traditional and intensive olive orchards through the development of new prototype air-assisted sprayers. Crop. Prot. 2017, 94, 44-58. [CrossRef]

37. Rautmann, D.; Streloke, M.; Winkler, R. New basic drift values in the authorization procedure for plant protection products. Mitt. Biol. Bundesanst Forstwirtsch 2001, 383, 133-141.

38. TOPPS-Prowadis Project. Best Management Practices to Reduce Spray Drift. 2014. Available online: http://www.topps-life.org/ (accessed on 7 September 2020).

39. Melese, E.A.; Debaer, C.; Rutten, N.; Vercammen, J.; Delele, M.A.; Ramon, H.; Nicolaï, B.M.; Verboven, P. A new integrated CFD modelling approach towards air-assisted orchard spraying. Part I. Model development and effect of wind speed and direction on sprayer airflow. Comput. Electron. Agric. 2010, 71, 128-136.

40. Herbst, A. A method to determine spray drift potential from nozzles and its link to buffer zone restrictions. In Proceedings of the ASAE Annual International Meeting, Sacramento, CA, USA, 28 July-1 August 2001. Paper number: 1-1047.

41. Doruchowski, G.; Swiechowski, W.; Holownicki, R.; Godyn, A. Environmentally-Dependent Application System (EDAS) for safer spray application in fruit growing. J. Hortic. Sci. Biotechnol. 2009, 86, 107-112. [CrossRef]

42. Hofman, V.; Solseng, E. Reducing Spray Drift; North Dakota State University NDSU Extension Service AE-1210; North Dakota State University NDSU Extension Service: Fargo, ND, USA, 2017. 
43. Van de Zande, J.C.; Holterman, H.J.; Wenneker, M. Nozzle classification for drift reduction in orchard spraying: Identification of drift reduction class threshold nozzles. Agric. Eng. Int. CIGR Ejournal 2008, 10, $1-12$.

44. Nuyttens, D.; de Schampheleire, M.; Verboven, P.; Brusselman, E.; Dekeyser, D. Droplet size and velocity characteristics of agricultural sprays. Trans. ASABE 2009, 52, 1471-1480. [CrossRef]

45. Garcerá, C.; Román, C.; Moltó, E.; Abad, R.; Insa, J.A.; Torrent, X.; Planas, S.; Chueca, P. Comparison between standard and drift reducing nozzles for pesticide application in citrus: Part II. Effects on canopy spray distribution, control efficacy of Aonidiella aurantii (Maskell), beneficial parasitoids and pesticide residues on fruit. Crop. Prot. 2017, 94, 83-96. [CrossRef]

46. Cawood, P.N.; Robinson, T.H.; Whittaker, S. An investigation of alternative application techniques for the control of blackgrass. In Proceedings of the Brighton Crop Protection Conference-Weeds, Brighton, UK, 20-23 November 1995; pp. 521-528.

47. Doruchowski, G.; Swiechowski, W.; Masny, S.; Maciesiak, A.; Tartanus, M.; Bryk, H.; Hołownicki, R. Low-drift nozzles vs. standard nozzles for pesticide application in the biological efficacy trials of pesticides in apple pest and disease control. Sci. Total Environ. 2017, 575, 1239-1246. [CrossRef] [PubMed]

48. Balsari, P.; Gil, E.; Marucco, P.; van de Zande, J.C.; Nuyttens, D.; Herbst, A.; Gallart, M. Field-crop-sprayer potential drift measured using test bench: Effects of boom height and nozzle type. Biosyst. Eng. 2017, 154, 3-13. [CrossRef]

49. Codis, S.; Verges, A.; Auvergne, C.; Bonicel, J.F.; Diouloufet, G.; Cavalier, R.; Douzals, J.P.; Magnier, J.; Montegano, P.; Ribeyrolles, X.; et al. Optimization of early growth stage treatments of the vine: Experimentations on the artificial vine EvaSprayViti. Proceedings of SuproFruit, 13th Workshop on Spray Application Techniques in Fruit Growing, Lindau/Lake Constance, Germany, 15-18 July 2015; pp. 47-48.

50. Porras Soriano, A.; Porras Soriano, M.L.; Porras Piedra, A.; Soriano Martìn, M.L. Comparison of the pesticide coverage achieved in a trellised vineyard by a prototype tunnel sprayer, a hydraulic sprayer, an air assisted sprayer and a pneumatic sprayer. Span. J. Agric. Res. 2005, 3, 175-181. [CrossRef]

51. Marucco, P.; Balsari, P.; Grella, M.; Pugliese, M.; Eberle, D.; Gil, E.; Llop, J.; Fountas, S.; Mylonas, N.; Tsitsigiannis, D.; et al. OPTIMA EU project: Main goal and first results of inventory of current spray practices in vineyards and orchards. In Proceedings of the SuproFruit, 15th Workshop on Spray Application and Precision Technology in Fruit Growing, East Malling, UK, 16-18 July 2019; pp. 99-100.

52. Grella, M.; Marucco, P.; Balsari, P. Evaluation of potential spray drift generated by different aypes of Airblast sprayers using an "ad hoc" test bench device. In Innovative Biosystems Engineering for Sustainable Agriculture, Forestry and Food Production, Proceedings of the MID-TERM AIIA, Matera, Italy, 12-13 September; Coppola, A., Di Renzo, G., Altieri, G., D’Antonio, P., Eds.; Springer: Cham, Switzerland, 2020; Volume 67, pp. 431-440. [CrossRef]

53. Balsari, P.; Grella, M.; Marucco, P.; Matta, F.; Miranda-Fuentes, A. Assessing the influence of air speed and liquid flow rate on the droplet size and homogeneity in pneumatic spraying. Pest Manag. Sci. 2019, 75, 366-379. [CrossRef]

54. Balsari, P.; Tamagnone, M.; Marucco, P.; Matta, F. How air liquid parameters affect droplet size: Experiences with different pneumatic nozzles. Asp. Appl. Biol. 2016, 132, 265-271.

55. Miranda-Fuentes, A.; Marucco, P.; Gonzalez-Sanchez, E.J.; Gil, E.; Grella, M.; Balsari, P. Developing strategies to reduce spray drift in pneumatic spraying vineyards: Assessment of the parameters affecting droplet size in pneumatic spraying. Sci. Total Environ. 2018, 616-617, 805-815. [CrossRef]

56. Byass, J.B.; Lake, J.R. Spray drift from a tractor-powered field sprayer. Pestic. Sci. 1977, 8, 117-126. [CrossRef]

57. Grover, R.; Kerr, L.A.; Maybank, J.; Yoshida, K. Field measurements of droplets drift from ground sprayers. I. Sampling, analytical and data integration techniques. Can. J. Plant Sci. 1978, 58, 611-622. [CrossRef]

58. Grella, M.; Miranda-Fuentes, A.; Marucco, P.; Balsari, P. Field assessment of a newly-designed pneumatic spout to contain spray drift in vineyards: Evaluation of canopy distribution and off-target losses. Pest. Manag. Sci. 2020. [CrossRef] [PubMed]

59. Matthews, G.A.; Hislop, E.C. Application Technology for Crop Protection, 1st ed.; C.A.B. International: Wallingford, UK, 1993; p. 359.

60. Wenneker, M.; van de Zande, J.C.; Stallinga, H.; Michielsen, J.M.P.G.; van Velde, P.; Nieuwenhuitzen, A.T. Emission reduction in orchards by improved spray deposition and increased spray drift reduction of multiple row sprayers. Asp. Appl. Biol. 2014, 122, 195-202. 
61. R Core Team. R: A Language and Environment for Statistical Computing; R Foundation for Statistical Computing: Vienna, Austria, 2019; Available online: https://www.R-project.org (accessed on 7 September 2020).

62. IBM Corp. IBM SPSS Statistics for Windows; Version 25.0; IBM Corp: Armonk, NY, USA, 2017.

63. American Society of Agricultural Engineers. ASABE S572.1 Spray Nozzle Classification by Droplet Spectra; American Society of Agricultural Engineers: St. Joseph, MI, USA, 2009; p. 4.

64. Southcombe, E.S.E.; Miller, P.C.H.; Ganzelmeier, H.; van de Zande, J.C.; Miralles, A.; Hewitt, A.J. The international (BCPC) spray classification system including a drift potential factor. In Proceedings of the Brighton Crop Protection Conference-Weeds, Brighton, UK, 17-20 November 1997; pp. 371-380.

Publisher's Note: MDPI stays neutral with regard to jurisdictional claims in published maps and institutional affiliations.

(C) 2020 by the authors. Licensee MDPI, Basel, Switzerland. This article is an open access article distributed under the terms and conditions of the Creative Commons Attribution (CC BY) license (http://creativecommons.org/licenses/by/4.0/). 